\title{
Fecundidade de jovens e acesso à saúde sexual e reprodutiva no Brasil: desigualdades territoriais*
}

\author{
Suzana Marta Cavenaghi*
}

\section{Resumo}

0 pleno acesso à saúde reprodutiva para jovens é um dos temas tratados no Programa de Ação da Conferência de População e Desenvolvimento de 1994, mas na América Latina pode-se afirmar que faz parte ainda de uma agenda inacabada e que necessita de atenção das políticas públicas que buscam o exercício pleno do direito à saúde sexual e reprodutiva. 0 padrão de fecundidade jovem é muito similar na região, em países ainda em transição da fecundidade e mesmo naqueles onde o nível de reposição populacional já foi ultrapassado. A situação do Brasil é um caso interessante, pois pode ser precursor de caminhos que outros países irão percorrer. 0 objetivo deste trabalho é apresentar um panorama regional sobre a atual situação da saúde reprodutiva das mulheres de 15-19 anos, que denominamos de adolescentes e jovens, assim como analisar a fecundidade destas mulheres. Para o estudo utilizou-se os dados censitários, incluindo os dados mais recentes do Censo Demográfico 2010, e os dados da Pesquisa de Demografia e Saúde de 2006. A análise sempre parte de uma perspectiva nacional e busca as desagregações possíveis em nível territorial. Os resultados mostram que mesmo tendo apresentado declínio da fecundidade das mulheres de 15-19 anos em 2010, após um aumento ocorrido na década de 1990, os diferenciais regionais são bastante altos.

Palavras-chave: Saúde Sexual e Reprodutiva. Fecundidade de Adolescentes. Desigualdades Territoriais. Censo Demográfico de 2010. PNDS de 2006.

\footnotetext{
*As opiniões expressas neste trabalho são de responsabilidade da autora e não necessariamente representam as do IBGE. Artigo originalmente publicado em espanhol em Notas de Población, N.96, Celade/ Cepal e publicado aqui com autorização.

" Professora e Pesquisadora na Escola Nacional de Ciências Estatísticas (ENCE/BGE) e Coordenadora da pósgraduação. Doutora e Mestre em Sociologia/demografia pela Universidade do Texas-Austin.
} 


\section{Introdução}

A população brasileira tem sido protagonista de uma história de transformações demográficas intensas nas últimas décadas. A transição da fecundidade é uma dessas transformações e está praticamente na sua etapa final, com a taxa de fecundidade total abaixo do nível de reposição. No entanto, o ritmo e a intensidade dessa mudança foram distintos para as mulheres nos diferentes grupos de idade. No Brasil, a queda da fecundidade foi acompanhada de um rejuvenescimento da estrutura etária, devido à diminuição relativa maior da fecundidade para as mulheres em idades medianas e mais avançadas no período reprodutivo. Com isso, não somente no Brasil, como na maioria dos países da América Latina, o tema da maternidade e da fecundidade de adolescentes e jovens é um tema que ganhou relevância nos anos mais recentes e este tem sido bastante discutido e com distintos matizes e variados pontos de vista.

Na Conferência de População e Desenvolvimento (CIPD) de 1994 o tema do acesso universal à saúde reprodutiva ganhou centralidade, no entanto, a questão da fecundidade de adolescente não teve destaque nos anos seguidos à divulgação do plano de ação (PA) da CIPD. Naquele momento, a taxa de fecundidade total estava em franco descenso em muitos países em desenvolvimento, mas a fecundidade de adolescentes não chamava tanta atenção quanto à resistência à queda no mesmo ritmo que ocorria para as demais faixas etárias. Adicionalmente, a saúde sexual, que de fato era um tema mais próximo à população jovem do que a saúde reprodutiva, não entrou no PA, ficando esta relegada para o segundo plano. Muitos anos depois, com a declaração dos Objetivos de Desenvolvimento do Milênio (ODMs), o acesso universal à saúde sexual e reprodutiva não foi incluído em suas metas (CORREA; ALVES, 2005). Somente em 2005, com a revisão dos 0DMs, já quando os estudos apontavam não somente para a resistência de queda da taxa de fecundidade de adolescentes, mas a ocorrência de um aumento dessa taxa na segunda metade da década de 1990 em alguns países em desenvolvimento, a fecundidade de mulheres de 15-19 anos passou a ter maior destaque, inclusive com a inclusão dessa na meta $5 \mathrm{~B}$, assim como outros indicadores de acesso a métodos contraceptivos (JIMENEZ; RODRIGUEZ-VIGNOLI, 2009).

0 Brasil, apesar da queda da fecundidade total continuada desde meados de 1960, chamou ainda mais atenção na década de 1990, quando além de apresentar altos níveis da taxa fecundidade de adolescentes e jovens mostrou um aumento desta de ao redor de 25\% (CAVENAGHI; BERQUÓ, 2005) entre 1991 e 2000. Diante deste quadro, é importante conhecer e acompanhar os dados de fecundidade e também as condições de acesso à saúde reprodutiva e os direitos sexuais e reprodutivos da população jovem e entender em que contexto estas situações de alta fecundidade se 
dão ou persistem. 0 estudo do caso do Brasil é icônico na América Latina por dois motivos. 0 primeiro, como já dito, o País apresenta fecundidade total abaixo do nível de reposição desde 2005 e ainda mantém a fecundidade de adolescentes em níveis altos. 0 segundo, que apesar de nunca ter tido políticas públicas explicitas dirigidas à regulação da fecundidade, tanto a geral quanto a de jovens, o País apresentou declínio importante da fecundidade de jovens na década de 2000 (CAVENAGHI; ALVES, 2011), diferente do que ocorreu em outros países da região que têm investido em programas de prevenção à gravidez não planejada, como, por exemplo, nos países andinos (ORGANISMO ANDINO DE SALUD, 2009), onde a fecundidade de jovens e adolescentes continua alta.

0 objetivo deste trabalho é analisar algumas das condições em que se dá 0 exercício da maternidade entre jovens de 15 a 19 anos no Brasil usando dados mais recentes, dividindo-o em duas partes, uma que apresenta uma análise das taxas de fecundidade e da maternidade no País e outra que trata da situação sobre a saúde sexual e reprodutiva, ambas as partes considerando os diferenciais territoriais. $\mathrm{Na}$ primeira parte do trabalho, é fornecida uma análise das taxas de fecundidade das mulheres adolescentes e jovens no Brasil, na última década, dando destaque aos diferenciais regionais, utilizando dados do Censo Demográfico 2010. Importante mencionar, que na análise da fecundidade também se apresenta inicialmente a discussão mais conceitual sobre a evolução da fecundidade no País, visto que para entender melhor 0 que acontece com a fecundidade de jovens não se pode desconectá-la das tendências gerais da fecundidade no País. Na segunda parte, apresenta-se o panorama sobre alguns aspectos importantes da saúde reprodutiva a partir de indicadores selecionados, com dados da Pesquisa Nacional de Demografia e Saúde (PNDS) de 2006, com os recortes regionais permitidos pela pesquisa, ou seja, Grandes Regiões e situação de residência urbana ou rural.

\section{A fecundidade e a maternidade de adolescentes e jovens}

Nesta seção, procura-se dar um panorama sobre a situação atual da fecundidade total e as tendências das últimas décadas e como a fecundidade nas idades de 15-19 anos compõe a vida reprodutiva das mulheres sempre colocando como ênfase a comparação regional. Primeiramente, apresenta-se uma breve abordagem teórica sobre a transição da fecundidade, em geral, e em particular como a fecundidade de adolescentes e jovens se coloca neste contexto. Em seguida, mostram-se as tendências da fecundidade em geral, situando a fecundidade de adolescentes e 
jovens no contexto do calendário da fecundidade geral. Na sequência, analisa-se a fecundidade específica para 0 grupo de 15 a 19 anos, buscando entender quais os grupos apresentam maiores níveis e maiores diferenciais, que devem ser ambos tomados em consideração no desenho de políticas públicas que visem dar acesso adequado aos direitos sexuais e reprodutivos. Por último, nesta seção é apresentada uma breve análise desde o ponto de vista do exercício da maternidade precoce, buscando entender um pouco melhor as heterogeneidades internas ao grupo de 15 a 19 anos de idade e apontando para uma discussão sobre as consequências deste evento na vida das mulheres.

\section{Breve abordagem sobre o comportamento da fecundidade no Brasil}

No Brasil, até o início da década de 1960, na média nacional, a taxa de fecundidade total (TFT) estava acima de 6 filhos por mulher. No entanto, a conjugação de fatores estruturais (no plano da infraestrutura econômica e das bases materiais da sociedade) e institucionais (no plano da superestrutura e das relações jurídicas e das políticas públicas) possibilitou o início da transição da fecundidade na segunda metade dos anos de 1960, com a subsequente aceleração do ritmo de queda nas décadas seguintes, até alcançar o nível de reposição (2,1 filhos), em 2005, e 0 valor de 1,9 filho por mulher segundo os dados do Censo Demográfico 2010.

0 regime de alta fecundidade, prevalecente na maior parte da história do Brasil, foi explicado por Carvalho, Paiva e Sawyer (1981) e Paiva (1985) como resultado da estrutura produtiva fundamentada em um sistema primário-exportador e em uma economia de subsistência que estimulava um padrão de casamento precoce, sem 0 uso regular de métodos contraceptivos. Segundo os autores, o processo de proletarização e modernização provocou a desestabilização do regime de alta fecundidade no Brasil através de mudanças que ocorreram em três níveis: 1) monetarização da economia; 2) ampliação e diversificação do cesto de consumo através da inclusão de bens industrializados; e 3) destruição da economia de base familiar (subsistência) e expansão e homogeneização do mercado de trabalho assalariado. A esses fatores estruturais, Merrick e Berquó (1983) acrescentam os seguintes determinantes da queda da fecundidade no Brasil: 1) aumento dos níveis educacionais e redução do analfabetismo, principalmente entre as mulheres; 2) aumento da taxa de participação feminina no mercado de trabalho; e 3) crescimento das expectativas de consumo entre os grupos de baixa renda.

No plano institucional, Faria (1989) mostra que quatro políticas públicas promovidas pelo Governo Federal, após 1964, tiveram efeitos não antecipados sobre a 
redução da fecundidade no Brasil: 1) política de crédito ao consumidor; 2) política de telecomunicações; 3) política de previdência social; e 4) política de atenção à saúde. Usando um arcabouço próprio dos enfoques culturais, 0 autor considera que as políticas públicas influenciaram na queda da fecundidade agindo como vetores institucionais (difusão) portadores de novos conteúdos de consciência (inovação). 0 autor ainda chama a atenção para o efeito perverso desse processo, pois a oferta de meios contraceptivos se deu, inicialmente, através dos mecanismos de mercado, fora do alcance do poder aquisitivo das camadas populares.

Esta perspectiva teórica foi comprovada pelos fatos históricos, pois tão somente em 1988 a Constituição brasileira definiu o planejamento familiar como um "direito dos casais" e, somente em 1996, com o objetivo de regulamentar $0 \S 7^{\circ}$ do art. 226 da Constituiçã̃o Federal, foi aprovada a Lei № 9.263 , que em seu artigo $2^{\circ}$ diz: "entende-se planejamento familiar como 0 conjunto de ações de regulação da fecundidade que garanta direitos iguais de constituição, limitação ou aumento da prole pela mulher, pelo homem ou pelo casal". A normatização desta lei foi o que permitiu que o Sistema Público de Saúde (SUS) pudesse oferecer os serviços de planejamento reprodutivo, incluindo a provisão de métodos contraceptivos e a esterilização feminina a toda população (BERQUÓ; CAVENAGHI, 2004). Apenas em 2005 foi lançada a "Política Nacional de Direitos Sexuais e Direitos Reprodutivos" de acordo com os princípios consensuados na CIPD do Cairo, de 1994. Isto significa que durante a maior parte do processo de transição da fecundidade a população brasileira em idade reprodutiva não teve acesso adequado aos meios de regulação da fecundidade por parte do Estado, mas, maiormente via mercado. Consequentemente, eram altos os níveis de gravidez indesejada e aborto, como mostrou Martine (1975; 1996).

A falta de acesso às políticas de saúde reprodutiva afetou principalmente as mulheres. Alves (1994) mostrou que os determinantes estruturais e institucionais que provocaram a redução dos níveis de fecundidade no Brasil tiveram impactos diferenciados por gênero e geração. Com base em Caldwell (1982), 0 autor argumenta que houve uma reversão do fluxo intergeracional de riqueza entre pais e filhos e que os ganhos de autonomia das mulheres foram fundamentais para a redução do tamanho da prole das famílias.

A queda da fecundidade no Brasil ocorreu em todas as regiões e classes sociais, contudo 0 início e o ritmo da queda transcorreram de maneira diferenciada. Como mostraram (CARVALHO; WOOD, 1994) as desigualdades socioeconômicas provocaram diferentes regimes reprodutivos, embora a transição de altas para baixas taxas de fecundidade estejam fortemente correlacionadas com os níveis de desenvolvimento socioeconômico (POTTER et al., 2010). Autoras como Perpétuo e Wong (2003) consideravam que a fecundidade no Brasil estava convergindo para o nível de reposição, enquanto Camarano (1996) discordava da tese da convergência. 
0 fato é que a transição da fecundidade no Brasil, além de ocorrer de maneira diferenciada segundo os níveis de renda e educação, ocorreu com uma tendência geral ao rejuvenescimento do padrão reprodutivo (BERQUÓ; CAVENAGHI, 2004; 2005) e manutenção da fecundidade de adolescentes e jovens em altos níveis. Processo que foi totalmente contrário ao do adiamento da idade do nascimento do primeiro fiIho, característica da segunda transição demográfica da Europa (VAN DE KAA, 1997). 0 que aconteceu no Brasil foi que as mulheres continuaram a ter filhos nas idades jovens e passaram a fazer o controle por parturição (parity-dependent fertility control) bem antes do fim do período reprodutivo. Com isto, 0 efeito tempo tem sido negativo na taxa de fecundidade de período (TFT), ou seja, a idade média da fecundidade foi reduzida concomitantemente ao processo de convergência para os níveis de reposição (RIOS-NET0 et al., 2005).

Foi neste contexto de acesso inadequado ao planejamento reprodutivo (ALVES, 2009), principalmente para a população mais pobre e residindo mais longe dos centros urbanos, mas com demanda forte por menor número de filhos, é que a transição da fecundidade ocorreu no País. Portanto, não se pode estranhar que a persistência da alta fecundidade de jovens fosse vista como um evento não explicado pelas teorias postas em discussão e algumas posições extremas fossem colocadas para entender o fenômeno. Essas explicações vão desde aquelas onde o tema é visto como um problema social que deve ser resolvido (prevenido), ao extremo oposto, onde é visto como comportamento normal, ou como estratégias de sobrevivência. Vale destacar que Furstenberg (1998) chamou atenção para como a experiência dos Estados Unidos poderia servir como exemplo para que nos países em desenvolvimento a maternidade entre os jovens não viesse a se configurar como um problema social. 0 autor chama atenção para o caso da Europa, onde a iniciação sexual se dá de forma segura e com apoio da família e nos Estados Unidos as diferentes mensagens, vindas da mídia, das políticas públicas e das famílias colocavam os adolescentes e jovens em uma situação de "fogo cruzado". Ainda, previu que se medidas apropriadas não fossem tomadas, que a fecundidade permaneceria alta e até poderia aumentar em países que estavam em processo de desenvolvimento econômico.

Os estudiosos do tema, no entanto, não apresentam consenso sobre quais são as causas para a permanência de altas taxas de fecundidade entre adolescentes e jovens, ou seja, quais as explicações que poderiam dar conta de entender este fenômeno em sua complexidade nos países em desenvolvimento. Muito se investiga sobre as consequências que este comportamento traz para a vida dos jovens, das crianças e da sociedade como um todo, e se confunde muito estas consequências com o que seriam as explicações para o fenômeno. Os fatores de risco, ou consequências sobre alta prevalência de maternidade em idade precoce, quando ganham a mídia viram sensacionalismos e muito vinculados à reprodução da pobreza e até 
mesmo vinculados ao aumento da violência em alguns casos. Tratar de temas vinculados à adolescência e à juventude, no entanto, deve ir além de disputas ideológicas ou de um campo do conhecimento, por se tratar do futuro das gerações. Assim, por um lado é importante buscar as respostas para as causas desse comportamento e, quando for adequado procurar soluções nas políticas públicas e nas relações familiares. Por outro lado, deve-se entender quais são as possíveis consequências desse comportamento para as mães, para os filhos e para as futuras gerações e atuar com políticas públicas adequadas para minimizar estes riscos.

A literatura tem mostrado que as causas do início do exercício da maternidade precoce passam por diversos fatores e em muitos casos devido a combinações destes. Um primeiro fator está vinculado a que alguns casais por motivos emocionais, independente do status social, econômico, educacional, etc., querem formar famílias cedo (STERN; GARCÍA, 2001). Uma segunda causa para a alta fecundidade entre jovens, principalmente entre as classes sociais mais pobres, está ligado à falta de projetos de vida alternativos à maternidade em países onde a educação de baixa qualidade e perspectiva de entrada no mercado de trabalho formal não incentivam os jovens, recorrendo estes então à formação de família precoce para mudança de status na sociedade, visto que este é projeto de vida viável (CORRÊA, 2009). Um terceiro fator apontado é a falta de informação adequada sobre o processo reprodutivo para os jovens, devido, em grande medida, à falta de educação sexual nos currículos escolares e isto não se resume a somente conhecer os métodos contraceptivos (HEILBORN, 2006). 0 quarto fator tem a ver com a deficiência no acesso e no uso adequado a métodos contraceptivos eficientes para prevenir a gravidez não planejada (HEILBORN, 2006; CAVENAGHI; BERQUÓ, 2005) em um momento da história onde a maior liberdade sexual, implica não somente no seu exercício a idades cada vez mais jovens, mas também a ocorrência desta com maior frequência na vida dos jovens (FURSTENBERG, 1998; CAVENAGHI; BERQUÓ, 2005), atreladas ainda à indisponibilidade de interrupção segura de gravidez não desejada. Um quinto motivo estaria vinculado à assimetria de gênero que existe nas relações entre os jovens, com baixo status e empoderamento das mulheres, que fazem em geral com que as negociações para a realização de sexo seguro aconteça de maneira inadequada (CASIQUE, 2012). Os dois primeiros fatores estão mais associados a questões psicossociais, outros mais vinculados à questão de saúde sexual e reprodutiva e 0 último a uma combinação desses. 0 que leva uma adolescente a engravidar e a levar esta gravidez a termo pode passar pela complexa relação entre todas estas causas e as condições socioeconômicas em que essas se deram.

As consequências de uma gravidez interrompida à idade jovem e a(s) gravidez(es) levadas a termo são outro rol de preocupações que também devem estar na pauta das políticas públicas e de investigação. A literatura trata dos riscos associados 
à saúde tanto da grávida quanto da criança, mas não existe um consenso com relação ao efeito desses riscos, pois não dependem somente da idade da grávida, visto que sempre estão associados a outros fatores, inclusive com relação à realização de um pré-natal adequado, que por sua vez pode estar vinculado a condições emocionais, sociais e econômicas. Além dos riscos à saúde, os riscos sociais e econômicos fazem parte de uma lista de efeitos comumente investigados, como, por exemplo, 0 risco de circulação maior das crianças (OLIVEIRA; VIEIRA, 2009), riscos associados ao aumento ou perpetuação da pobreza, aumento da violência e riscos associados à baixa educação das jovens mães (AQUINO et al., 2003).

A dificuldade em se tratar da maternidade precoce ${ }^{1}$ como um problema e a confusão entre causas e consequências, muitas vezes toma como base estudos que apontam que as mulheres jovens veem como altamente positivas suas experiências de maternidade. No entanto, como bem aponta a demógrafa Elza Berquó, sobre a experiência de maternidade em idades muito jovens "Em geral, essa visão positiva é post facto, ou seja, uma forma de aceitar algo já posto" (HAAG, 2012, p.90) e não um projeto de vida baseado na maternidade. Isto não significa que não existem casos onde 0 projeto é a maternidade iniciada a idades jovens, no entanto, a maioria dos nascimentos (sem contar gravidezes) que ocorrem antes das mulheres completarem 20 anos não foi planejada no caso do Brasil. Estes casos somaram quase $70 \%$ para mulheres com 15-19 anos de idade em 2006, segundo Borgato e Oliveira (2011).

Neste trabalho, parte-se do pressuposto que a ocorrência da maternidade em idade jovem que se deu por falta de planejamento (que não era desejada para aquele momento) deve ser realmente encarada como um problema de falta de acesso adequado aos direitos sexuais e à saúde reprodutiva e não somente um problema social. Ainda, entende-se que a resistência em ver o fenômeno como um problema ou uma questão de política pública é inadequado se analisado no contexto mais geral do quadro demográfico e socioeconômico do País. No Brasil de hoje, as mulheres vivem muito mais que no passado, onde a esperança de vida passou de ao redor de 40 anos para 77 anos; a fecundidade total no País está abaixo do nível de reposição (1,9 filho em média por mulher); ao redor de $65 \%$ das mulheres em idade reprodutiva participam do mercado de trabalho; e, apesar de ainda ter poucos anos de estudo e uma educação de baixa qualidade, as mulheres passaram os homens em termos educacionais. Diante destas mudanças, se esperaria que, como nos países mais desenvolvidos, as mulheres mudassem seu comportamento reprodutivo, adiando 0 nascimento dos filhos, pelo menos até terminar os estudos e entrar em um mercado de trabalho formal. De fato, o que ocorre no Brasil é que a qualidade da educação

\footnotetext{
${ }^{1} 0$ termo maternidade precoce inclusive é evitado ou utilizado entre aspas por alguns autores para não vincular a juízos de valor.
} 
é ainda muito baixa, principalmente para a população mais pobre e para conseguir trabalho decente as mulheres devem transpor muitas barreiras. Os eventos demográficos permitiriam uma transformação enorme no ciclo de vida das mulheres, mas somente parte desta população logrou esta mudança.

0 cenário se complica ainda mais, visto que iniciar a fecundidade em idade jovem poderia levar a um número final de filhos muito maior do que o planejado. É comum ver citado na literatura dos anos de 1990 que este início da fecundidade em idades jovens levaria as mulheres a terem muitos filhos durante a vida reprodutiva (CAMARANO, 1998). No entanto, este início do exercício da maternidade em idades jovens, sob a demanda de poucos filhos, de fato coloca as mulheres por um longo período expostas a gravidezes não desejadas e as opções por métodos contraceptivos mais eficazes ou permanentes serão uma realidade entre as mulheres jovens, ou diante da falta desses, um cenário ainda pior, a realização de interrupção da gravidez de maneira insegura, visto que no País o aborto é ilegal, com algumas exceções.

\section{Dados e metodologia}

As análises da fecundidade e da maternidade são realizadas com base nos microdados dos Censos demográficos brasileiros, com especial atenção aos dados mais recentes, de 2010. Para o cálculo da fecundidade, são utilizadas as informações sobre 0 número de filhos nascidos vivos e de filhos nascidos no ano precedente à data de referência do Censo Demográfico, classificados por idade das mulheres. Estes dados são provenientes da parte amostral do censo, com tamanho variável ao longo dos anos. A amostra de 1980 foi de $25 \%$ dos domicílios, em 1991 e 2000 foram duas frações amostrais, de $10 \%$ dos domicílios para os municípios com mais de 15 mil habitantes estimados e 20\% para os municípios menores. Em 2010, foram utilizadas várias frações amostrais que variaram por número de habitantes estimados nos municípios, com tamanhos amostrais de $5 \%$ a $50 \%$, respectivamente dos maiores aos menores municípios (IBGE, 2010).

0 grupo de mulheres de 15-19 anos de idade foi selecionado para as análises sobre fecundidade e maternidade. Vale destacar que entrevistar mulheres menores de 15 anos traria complicações éticas muito grandes para a pesquisa e mais, traria problemas metodológicos para realizar análises sobre fecundidade deste grupo etário $^{2}$. Apesar de a fecundidade de menores de 15 anos ser um problema muito sério,

${ }^{2} 0$ Censo Demográfico no Brasil inclui informações para mulheres de 10-14 anos, no entanto, a informação é dada pelo entrevistado, que pode ou não ser a própria pessoa. 
e muitas vezes vinculado à violência de gênero, a raridade do evento, em termos estatísticos, torna impossível coletar este tipo de informação em pesquisa amostral e fazer análises desagregadas regionalmente. Deve-se esclarecer também que a idade de 19 anos foi selecionada como grupo superior para identificar jovens, mas isto não significa que não se considera 0 grupo de 20 a 24 anos como jovem também. No entanto, o grupo de jovens apresenta heterogeneidades internas tão grandes que incorporar o grupo etário seguinte tornaria a análise ainda mais complexa. Finalmente, em relação ao termo 'adolescentes e jovens' procura-se utilizar este ao longo do texto, exatamente porque 0 grupo de 15-19 anos de idade é muito heterogêneo e seria incorreto denominar de adolescentes as mulheres que já fizeram a transição para a vida adulta, principalmente através da maternidade, que é foco de análise neste trabalho.

De fato, faz-se necessário um esclarecimento metodológico importante, que em geral é esquecido nos estudos sobre gravidez em idades jovens, ou seja, a diferença entre maternidade, fecundidade e gravidez. Os dados disponíveis na maioria dos países latino americanos somente permitem análises sobre maternidade $\mathrm{e}$ fecundidade, visto que informações sobre gravidez quase inexistem e na maioria dos países 0 aborto induzido é ilegal, deixando de fora a contagem de muita gravidez que termina em aborto. Um estudo de fato sobre gravidez na juventude, ou um programa de política pública para prevenir gravidezes não planejadas, deveria ter no mínimo dados sobre aborto induzido. Alguns programas de prevenção da gravidez não planejada na adolescência não mencionam 0 aborto como indicador importante para o devido mapeamento do problema como, por exemplo, o Programa dos países Andinos (ORGANISMO ANDINO DE SALUD, 2009). A ilegalidade acaba mascarando a realidade de prática de aborto induzido inseguro, principalmente importante em mulheres que ainda pretendem ter uma vida reprodutiva mais adiante e podem se tornar estéreis devido a abortos inseguros. De toda forma, o fato que se resgata aqui é que os dados de taxas de fecundidade (ou índices de maternidade) que são analisados neste trabalho, que são considerados altos na região, seriam ainda mais altos se fossem considerados dados de gravidez (ou pelo menos aborto induzido) e não somente dados sobre nascidos vivos. Para o caso do Brasil, apesar de 0 aborto ser ilegal na maioria das situações, com exceção de risco de vida da mãe e da criança e mais recentemente em casos de anencefalia, 0 aborto ilegal e inseguro na maior parte das vezes é muito utilizado (DINIZ; MEDEIROS, 2010). Estimativas indiretas mostram que para cada mil mulheres de 15-19 anos de idade houve 13,1 abortos induzidos no ano de 2010 no Brasil, quando a taxa para o País era de 11,6 (RISI; CAVENAGHI, 2012).

Como se sabe, as estimativas de fecundidade por usarem dados da parte amostral da pesquisa estão sujeitas a erros amostrais, além dos erros não amos- 
trais conhecidos para estas variáveis, como esquecimento e erro de declaração de idade. 0 menor nível geográfico de análise para a fecundidade neste trabalho é a situação rural dos estados, onde o menor deles é a área rural do Estado do Pará. Neste, por exemplo, o coeficiente de variação (CV) para a menor estimativa (filhos nascidos no último ano de mulheres de 15-19 anos) é ao redor de 4,5\% (em média 400 crianças). Para os demais estados, o CV é ainda menor, visto que as estimativas populacionais menores são ao redor de 2000 pessoas. Com relação à variável educacional, o resultado para grupos educacionais mais altos deve ser visto com mais cuidado, já que as estimativas de número de filhos nascidos no último ano podem estar ao redor ou inferior a 100 casos e, para estes casos, se tem um CV aproximado de 10\% (IBGE, 2010).

0 método utilizado para estimar a fecundidade das mulheres de 15-19 anos de idade foi o método indireto conhecido como P/F de Brass (UNITED NATIONS, 1983) e ajustado devido à subestimação das informações sobre fecundidade corrente ${ }^{3}$. Importante destacar que os dados de 1980 e 1991 foram corrigidos pelo método de El Badry, para correção de não resposta, mas os dados de 2000 e 2010 não necessitaram desta correção, dado que a porcentagem de não declaração de fecundidade foi muito pequena, além de não apresentar padrão conhecido ${ }^{4}$. É importante destacar que para o grupo de 15-19 anos de idade os dados são menos confiáveis, por este motivo, o P/F é usado para corrigir o nível da fecundidade declarada e não somente verificar qualidade da informação, visto que em geral para este grupo o nível declarado é mais baixo do que o nível esperado.

Para a análise da maternidade, foram utilizados indicadores simples definindo como mães as mulheres que tiveram pelo menos um filho nascido vivo ${ }^{5}$. Aqui vale ressaltar que não se trata de gravidez em idades jovens, visto que muitas gravidezes são terminadas voluntária ou involuntariamente e outras terminam em nascidos mortos. Para a análise geográfica do exercício da maternidade de mulheres de 15-19 anos, foram utilizadas as malhas digitais do Censo Demográfico 2010

\footnotetext{
${ }^{3}$ Apesar de outros métodos também apresentarem resultados consistentes, como o Método de Gompertz com solução de ZABA (MOULTRIE e DORRINGTON, 2008), o método P/F apresenta resultados bastante consistentes para o grupo de 15-19 e 20-24 anos, e tem aplicação muito mais simplificada e menos subjetiva que outros métodos.

${ }^{4}$ De toda forma, a porcentagem de não declaração de fecundidade foi baixa nos Censos Demográficos 1980 e 1991, visto que na etapa de crítica dos dados houve correção de não resposta para os dois primeiros grupos etários. Nos Censos 2000 e 2010, por política interna do IBGE, os dados praticamente não tiveram não declaração, pois dados faltantes e inconsistentes foram imputados durante a crítica dos dados.

${ }^{5}$ Vale lembrar que no Brasil a grande maioria dos Municípios tem população muito pequena (ao redor de $25 \%$ dos Municípios têm menos de 5 mil habitantes) e, portanto, as estimativas de mulheres de 15-19 anos com pelo menos um filho nesses Municípios podem ter coeficientes de variação maior que 10\%. De fato, em 39 desses, nenhuma mulher de 15-49 anos tinha sido mãe até a data de referência do Censo.
} 
com escalas geográficas em nível de mesorregiões, microrregiões e Municípios ${ }^{6}$. 0 método utilizado para classificação das categorias de porcentagem de mães para 0 mapeamento temático foi dividir o País em quintis com base nos dados por mesorregião e manter os mesmos intervalos para a divisão de microrregiões e Municípios para poder manter a comparabilidade entre as três escalas.

Em 2010 existiam 137 mesorregiões no País, as quais são, segundo o IBGE (2003), um "Conjunto de microrregiões, contíguas e contidas na mesma Unidade da Federação, agrupadas com base no quadro natural, no processo social e na rede de comunicações e de lugares" (p.224). As microrregiões eram 558, definidas como "Conjunto de Municípios, contíguos e contidos na mesma Unidade da Federação, agrupados com base em características do quadro natural, da organização da produção e de sua integração" (p. 224). Finalmente, havia 5565 municípios, que são as menores unidades político-administrativas autônomas no País. Apesar de a regionalização de micro e meso áreas ter sido criada a partir da busca por maior homogeneidade interna com relação às variáveis sociais e econômicas, como foram criadas em 1976, muita mudança ocorreu desde aquele momento, mas estas subdivisões ainda não sofreram alterações em suas delimitações. Estas áreas variam não somente em extensão territorial, mas também em população residente. As mesorregiões têm de 53613 até 21142508 habitantes; as microrregiões variam de 2629 a 13793504 habitantes; e os municípios são obviamente os que mais variam, existem municípios com 805 habitantes até um município enorme, com 11224369 pessoas residentes, como é o caso do Município de São Paulo. Estes diferentes domínios populacionais podem exercer alguma influência no resultado do indicador que se analisa aqui, por este motivo, alguns deles devem ser interpretados com cuidado e para uma análise mais detalhada, deveria ser considerado 0 uso de algum método de suavizamento de taxas e porcentagens para reduzir efeito de pequenos domínios, no entanto o objetivo aqui é somente apresentar o potencial de conhecimento da ocorrência da maternidade quando o detalhamento geográfico é tomado em consideração e não buscar as melhores estimativas desses indicadores.

\footnotetext{
${ }^{6} \mathrm{~A}$ menor área identificável a partir da amostra do Censo Demográfico brasileiro é a área de ponderação, que é um agregado de setores censitários que assegura confiabilidade estatística aos dados da área. Buscouse apresentar o resultado para áreas de ponderação, no entanto, devido às mudanças na base territorial e mudanças no cálculo das áreas de ponderação, principalmente com relação às mudanças na fração amostral, a malha digital em nível de área de ponderação ainda não está disponível.
} 


\section{Estrutura da fecundidade: concentração em idades jovens}

A fecundidade no Brasil, um pais de mais de 190 milhões de habitantes, chegou abaixo do nível de reposição em meados da década de 2000 e, segundo os dados do Censo Demográfico 2010, atingiu a média de 1,9 filho por mulher. Até o momento, os indicadores mostram que 0 efeito tempo da fecundidade, que foi positivo nas últimas décadas, passaria a ser negativo (MIRANDA-RIBEIR0 et al., 2008), indicando uma continuidade deste declínio, e o País, desta forma, atingiria níveis de fecundidade baixíssima no futuro próximo.

Com base na experiência de outros países com fecundidade baixa, poderia se inferir que 0 Brasil estaria seguindo 0 caminho dos países mediterrâneos como a Itália, Espanha e Portugal, onde a fecundidade já é considerada baixíssima (LESTHAEGHE; WILLEMS, 1999; KOHLER; BILLARI; ORTEGA, 2002). No entanto, a história não se repete completamente quando se compara países latino-americanos $\mathrm{e}$ europeus, como mostrado no Gráfico 1 com relação à estrutura de fecundidade, visto que apesar das baixas taxas de fecundidade, o padrão por idade é muito diferente.

Gráfico 1 países selecionados: Taxa de fecundidade específica por idade. Década de 2000

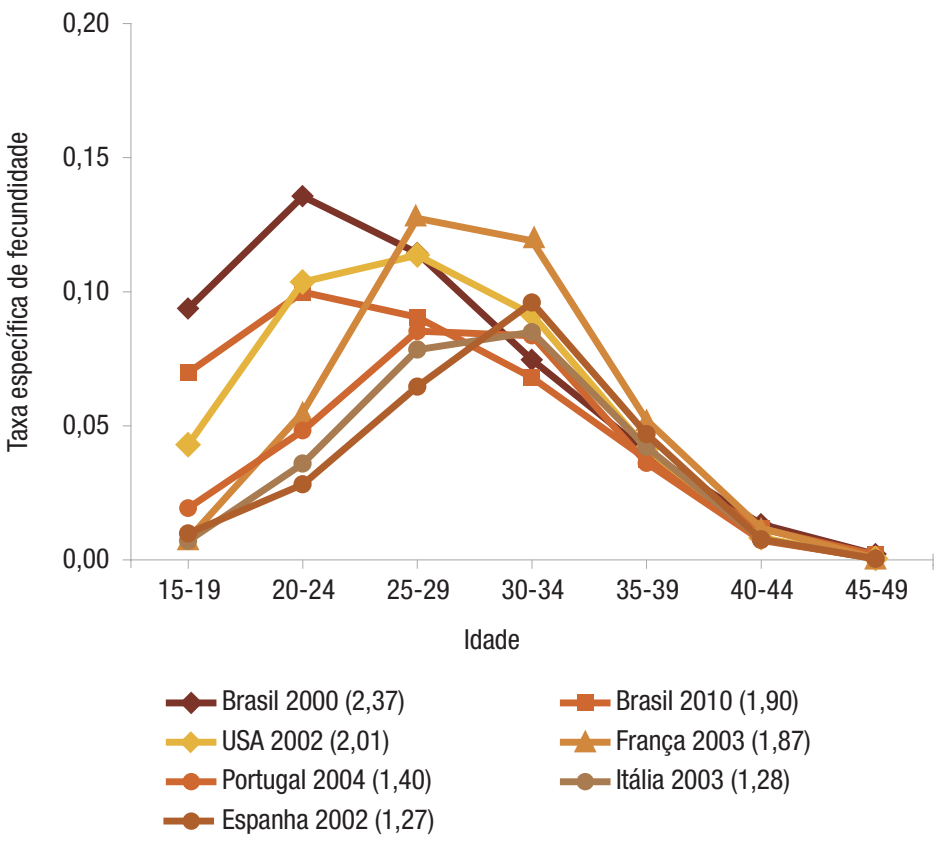


Nos países mediterrâneos, as mulheres até 24 anos têm fecundidade baixa e 0 mesmo ocorre com a França, que de fato tem TFT maior que a dos países mediterrâneos, mas esta ocorre com maior frequência para mulheres entre 25 e 34 anos de idade. Outro comportamento distinto, e intermediário aos anteriores, é o caso dos Estados Unidos, que apesar de apresentar fecundidade em nível de reposição, também apresenta fecundidade de adolescentes e jovens relativamente altas, e a maioria dos nascimentos ocorre para mulheres entre 20 e 29 anos de idade.

0 Brasil, além de apresentar um padrão etário da fecundidade muito jovem, este rejuvenesceu muito entre 1980 e 2000, como pode ser inferido a partir do Gráfico 2. A fecundidade das adolescentes e jovens (mulheres de 15-19 anos) declinou na última década e alcançou um patamar abaixo da fecundidade observada para as últimas três décadas e, segundo o Censo 2010, nasciam 70 crianças a cada mil mulheres de 15-19 anos. Mesmo assim, as taxas brasileiras são altas quando comparadas com outros Países: apenas 2,3 por mil na Coreia do Sul; de 8,4 por mil na China; de 29,5 por mil no Irã; de 7 por mil na França; de 11,6 por mil na Arábia Saudita; de 34 por mil nos Estados Unidos e de 59 por mil na África do Sul. Da mesma forma, as mulheres de 20-24 anos, também jovens, são as que apresentam o maior nível de fecundidade,

Gráfico 2 Brasil: Taxas específicas de Fecundidade, 1980 - 2010

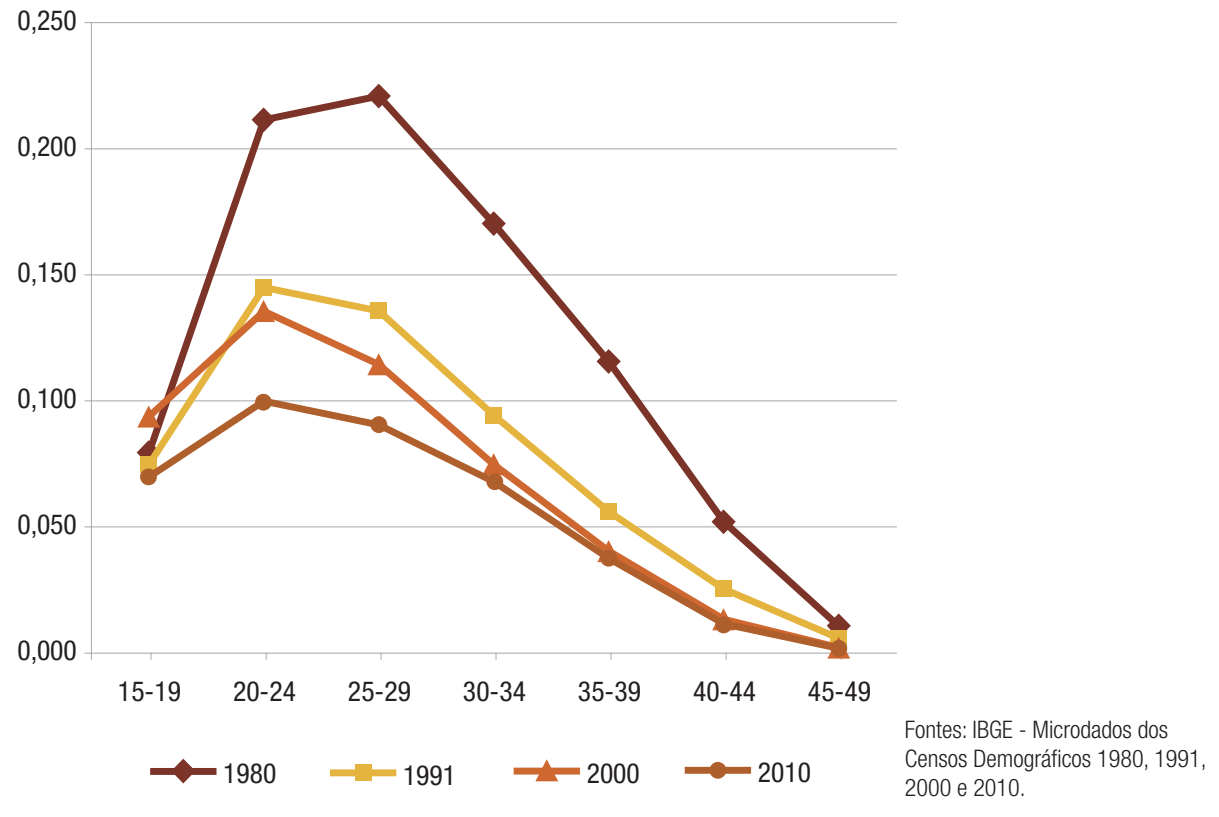


Gráfico 3 Brasil: Taxas específicas de fecundidade (A) e distribuição relativa (B) por idade, segundo os grupos etários e local de residência e as regiões, 2010.
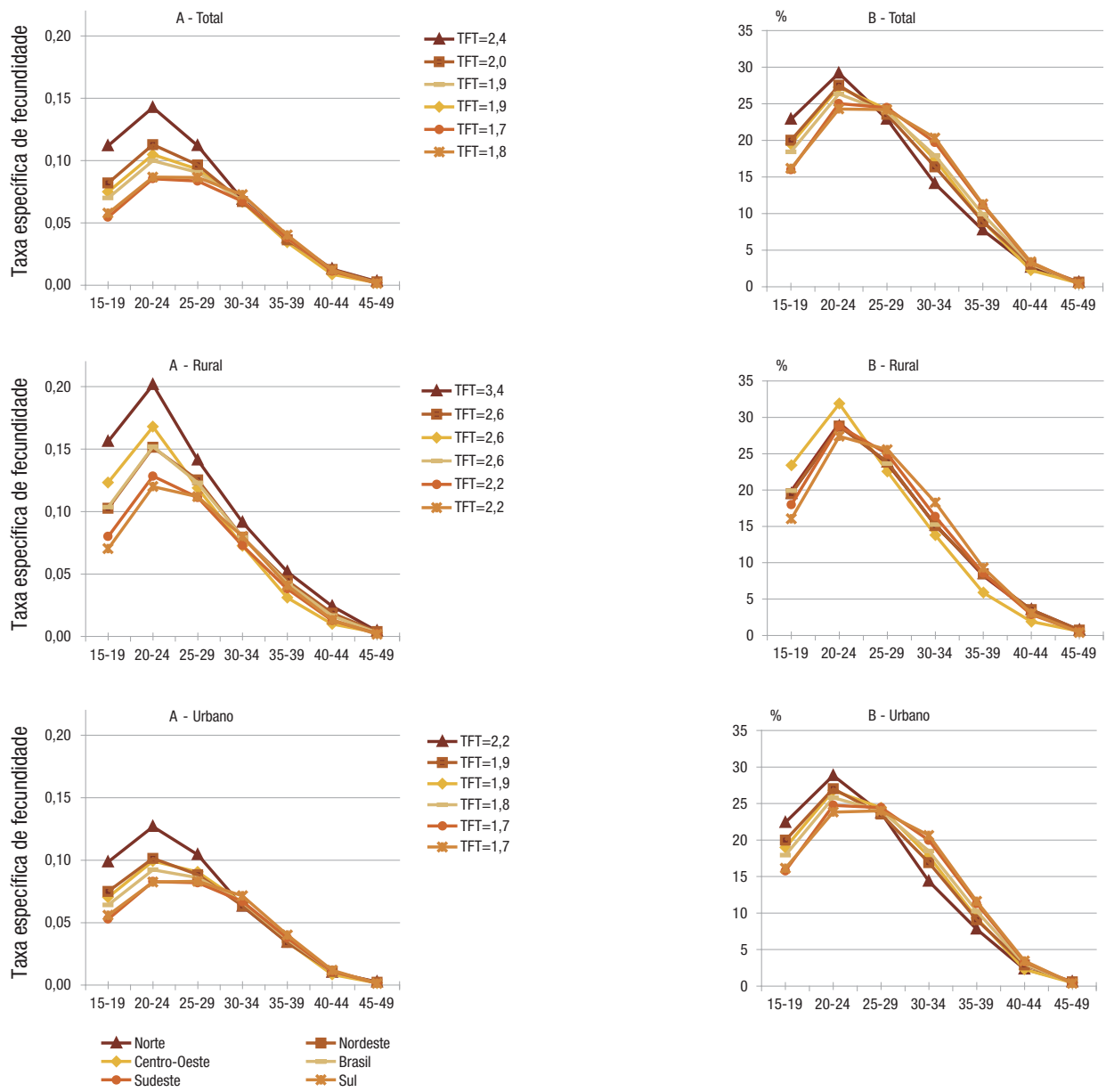

Fonte: IBGE - Microdados do Censo Demográfico 2010. 
mas foram elas que apresentaram maior queda na taxa na última década. Entretanto, dado que a fecundidade das mulheres acima dos 30 anos está muito baixa e a fecundidade das mulheres com 15-19 anos diminuiu na década, a curva da fecundidade não apresenta mais rejuvenescimento, inclusive apontando para um processo de envelhecimento da curva no futuro se as tendências atuais continuarem.

Este padrão jovem da fecundidade é observado regionalmente em todo o País. 0 Gráfico 3 mostra as distribuições das taxas específicas de fecundidade por idade (painel A) e a distribuição relativa destas (painel B) para as cinco regiões e para as áreas urbana e rural para 0 ano de 2010. Nos Gráficos apresentados no painel A, algumas características merecem maior destaque. Primeiro que a fecundidade das mulheres de 30 anos ou mais de idade é muito parecida independente da região considerada, mais ou menos desenvolvida, com pequenas diferenças ainda presente na área rural. Segundo que para os grupos mais jovens, de 15 a 29 anos de idade, principalmente os dois primeiros, ainda existem diferenciais significativos na taxa de fecundidade entre as regiões e os maiores diferenciais estão presentes na zona rural. Em terceiro lugar, mesmo para a área urbana das regiões mais desenvolvidas a curva de fecundidade ainda apresenta um padrão bastante jovem, com fecundidade das mulheres de 15-19 anos de idade da ordem de 50 nascimentos para cada mil mulheres. Em quarto lugar, no outro oposto se encontra a área urbana das regiões menos desenvolvidas, com a taxa de fecundidade de 15-19 anos alcançando valor ao redor de 150 nascimentos para cada mil mulheres, taxas equivalentes a países com TFT alta, como alguns países da África.

0 painel B do Gráfico 3 mostra que apesar do diferencial na TFT para as regiões e para a situação de domicílios urbano e rural ainda serem grandes no País, a estrutura da fecundidade é muito parecida em todas elas. A maior concentração da fecundidade, sem exceção, está no grupo de 20-24 anos de idade e 0 grupo de 25-29 apresenta 0 segundo maior valor para a maioria das Grandes Regiões. No entanto, em algumas regiões, em geral as menos desenvolvidas, o segundo maior valor relativo é apresentado para o grupo mais jovem (15-19 anos). Outro aspecto importante a ser destacado é que as curvas nas regiões menos desenvolvidas apresentam-se mais rejuvenescidas que nas demais regiões. Isto é devido a que a fecundidade das mulheres mais jovens é mais alta nestas regiões e as mulheres param de ter filhos mais cedo.

\section{Tendências e níveis diferenciais da fecundidade das adolescentes e jovens}

As taxas de fecundidade de jovens e adolescentes apresentam diferenciais regionais e socioeconômicos muito grandes na América Latina e têm-se mostrado resisten- 
tes a declinar, em tendência distinta das demais idades (RODRIGUEZ-VIGNOLI, 2011). 0 Brasil não foge a esta regra, mas por outro lado, a tendência de aumento visto na década de 1990 reverteu nos anos de 2000, dando sinais importantes de queda continuada, mas com limites altos bastante visíveis. Este fato é importante quando comparado a outros países latino-americanos, pois o Brasil além de nunca ter tido uma política explicita para diminuição da fecundidade total, tampouco realizou ações específicas para reduzir a fecundidade de adolescentes, mesmo depois de constatado 0 aumento nesta taxa na década passada.

A Tabela 1 mostra as taxas de fecundidade para as mulheres de 15-19 anos para as duas últimas décadas e a variação destas para mulheres residentes nas áreas rurais e Grandes Regiões. Na década de 1990 houve um aumento da taxa de fecundidade em todas as regiões e áreas, com maior aumento para 0 urbano e regiões mais desenvolvidas. Este aumento foi confirmado por várias fontes de dados, como a Pesquisa Nacional de Demografia e Saúde de 1986 e 1996, assim como a Pesquisa Nacional por Amostra de Domicílios (PNAD) para vários anos, apesar de variações por causa do tamanho da amostra, como analisado por Berquó e Cavenaghi (2005). Os motivos deste aumento são discutidos no trabalho e apontam, principalmente, para as mudanças em valores e atitudes na sociedade brasileira que ocorreram sem serem acompanhadas por mudanças na família e sem 0 apoio do estado. Estas mudanças foram a maior liberdade sexual, valores da virgindade relativizados, primeiras relações sexuais em idades mais jovens. E isto, aliado à falta de programas

Tabela 1 Brasil: Taxas específicas de fecundidade de mulheres de 15-19 anos de idade (por 1 000) segundo o lugar de residência e as Grandes Regiões - 1991, 2000 e 2010

\begin{tabular}{lccccc} 
& \multicolumn{3}{c}{ Taxas (por mil) } & \multicolumn{3}{c}{ Variação (\%) } \\
\cline { 2 - 6 } Lugar de residência e região & 1991 & 2000 & 2010 & $91-2000$ & $2000-10$ \\
\hline Brasil & 74,8 & 93,8 & 69,9 & 25,4 & $-25,5$ \\
\hline Urbano & 67,7 & 87,2 & 64,2 & 28,8 & $-26,4$ \\
\hline Rural & 100,5 & 125,9 & 103,6 & 25,2 & $-17,7$ \\
\hline Região & & & & & \\
\hline Norte & 124,8 & 145,0 & 111,8 & 16,1 & $-22,9$ \\
\hline Nordeste & 87,1 & 107,3 & 81,9 & 23,2 & $-23,7$ \\
\hline Sudeste & 60,0 & 76,2 & 54,5 & 26,9 & $-28,4$ \\
\hline Sul & 66,9 & 82,6 & 57,7 & 23,5 & $-30,2$ \\
Centro-0este & 90,6 & 107,1 & 74,9 & 18,3 & $-30,1$
\end{tabular}

Fonte: IBGE - Microdados dos Censos Demográficos 1991, 2000 e 2010. 
de planejamento reprodutivos adequados para adolescentes e jovens, falta de educação sexual no currículo escolar e persistência na assimetria de gênero. Analisando os dados do início da década, a partir do registro de nascimentos e PNADs, as autoras afirmaram que a fecundidade das jovens não continuava aumentando e, de fato, apontava para uma diminuição, apesar de não poderem estimar o tamanho real desse declínio (BERQUÓ; CAVENAGHI, 2005). Como não havia nenhum programa ou política pública dirigida a diminuir a fecundidade ${ }^{7}$, os motivos colocados pelas autoras para explicar esta diminuição foram, em primeiro lugar, advindos dos resultados das amplas campanhas em nível nacional para prevenção de DST e AIDS direcionadas para segmentos da população jovem e, como resultado, o maior uso de preservativo masculino, mas também a exposição massiva na mídia das consequências negativas da gravidez não planejada entre pessoas jovens.

De fato, como pode ser observado na Tabela 1, segundo os dados de 2010, na década passada houve uma diminuição generalizada da taxa específica de fecundidade para 0 grupo de 15-19 anos de idade, com decréscimos da ordem de $18 \%$ a $30 \%$. As regiões com menor decréscimos foram, em geral, aquelas menos desenvolvidas. Chama atenção a Região Centro-0este que foi a região que teve um dos menores aumentos na década anterior, e tem o maior decréscimo nos anos de 2000. Mesmo com o declínio da taxa, tanto o nível continua bastante alto quanto 0 diferencial entre as regiões continua acentuado. A menor taxa é encontrada na Região Sudeste, com ao redor de 55 nascimentos a cada mil mulheres. A maior taxa, de outro lado, é encontrada na região menos desenvolvida, a Região Norte, com quase 112 nascimentos a cada mil mulheres (Tabela 1).

Como amplamente documentado, o processo de desenvolvimento econômico e social do Brasil se deu de maneira desigual e heterogênea. 0 mesmo aconteceu historicamente com a dinâmica demográfica. Assim, o processo de transição da fecundidade se deu de maneira diferenciada entre as Unidades da Federação e entre os segmentos sociais. Em geral, a queda começou antes e seguiu um ritmo mais rápido nos estados mais desenvolvidos e nos segmentos de maior renda e escolaridade da população. Em 2010, podemos observar que internamente às Grandes Regiões, 0 diferencial de fecundidade de adolescentes e jovens é grande, variando na Região Norte de 90 para 120 por mil (Gráfico 4 - Painel A). As regiões com menores diferenciais na taxa de fecundidade de jovens entre os estados são aquelas mais desenvolvidas e a região mais desigual internamente é a Região Centro-0este, dado que Brasília se destaca dos demais estados da região, com taxas perto de 90 por mil e Brasília com uma das mais baixas do País, ao redor de 49 por mil.

\footnotetext{
${ }^{7}$ Na década houve discussão sobre a implementação de programas de educação sexual na escola, com algumas ações muito pontuais, e surgiu no início da década de 2000, também, 0 uso da contracepção de emergência, com distribuição em alguns centros de saúde.
} 
Gráfico 4 Taxas específicas de fecundidade (por mil) de mulheres de 15-19 anos de idade, segundo o lugar de residência e as Unidades da Federação, Brasil, 2010
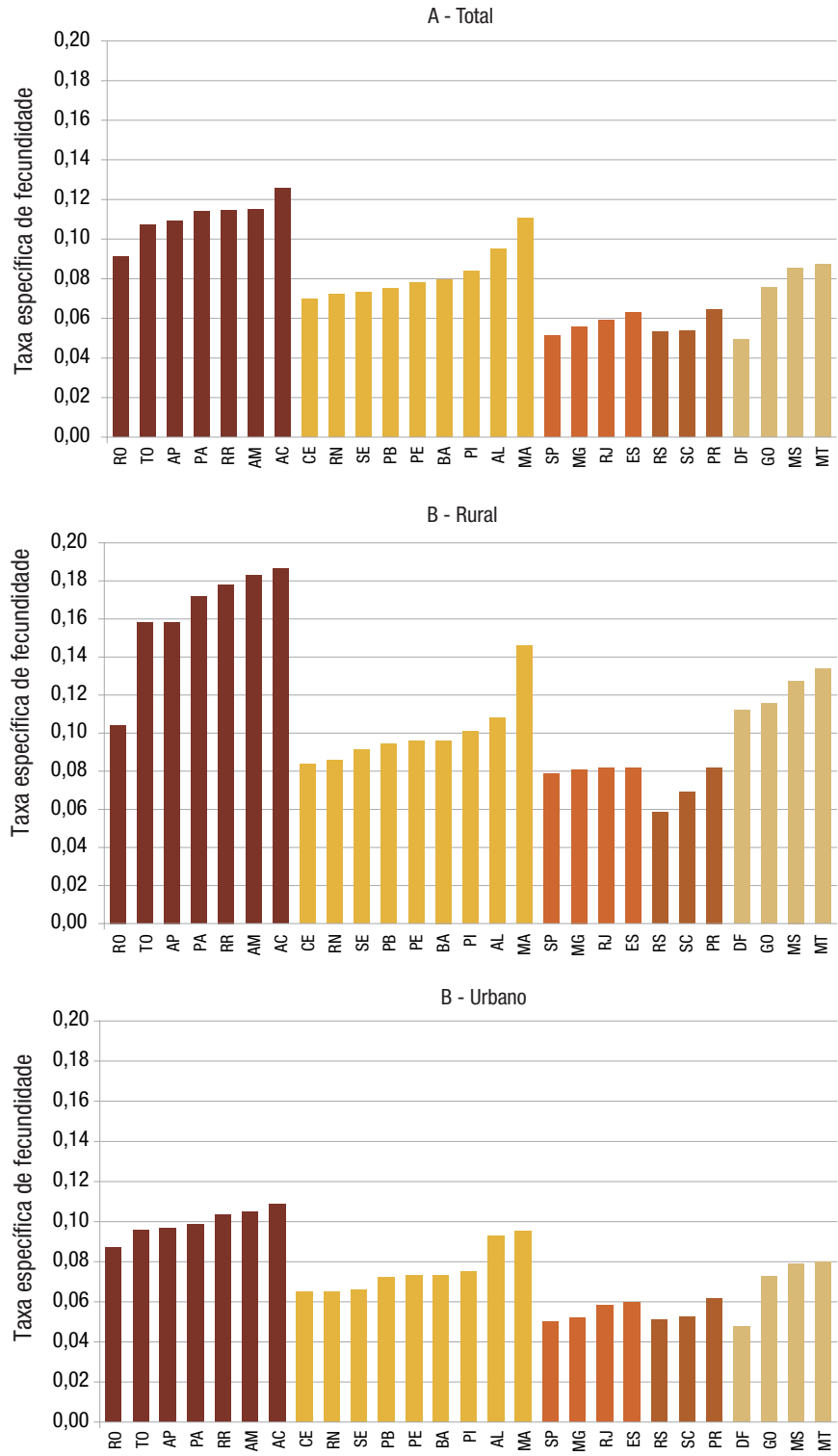

Fonte: IBGE - Microdados do Censo Demográfico 2010.

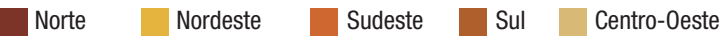


Como sempre, os níveis das taxas de fecundidade da área rural são maiores do que da área urbana para todos os estados, sem exceção. No entanto, os painéis $B$ e $C$ do Gráfico 6 comprovam que aquilo que pode-se denominar de comportamento urbano e rural depende muito da região. A área rural da Região Sudeste, com relação à fecundidade de jovens e adolescentes, é bastante homogênea, com taxas ao redor de 80 por mil, acima da média nacional, mas a área urbana é menos homogênea, apesar de apresentar taxas abaixo da média nacional. Isto se dá pela enorme diversidade econômica que existe nas regiões urbanas brasileiras, onde convivem pessoas de altíssima renda e pessoas abaixo do nível de pobreza. 0 inverso se dá na Região Sul, pois a área urbana apresenta-se mais homogênea com relação às taxas de fecundidade de adolescentes e jovens, onde Santa Catarina e Rio Grande do Sul apresentam situações mais similares, e a área rural apresenta diferencial importante, entre os três estados.

As variações internas da taxa de fecundidade de jovens na área rural das Regiões Norte e Nordeste também apresentam características peculiares. Apesar de haver um diferencial grande entre a menor e a maior taxa dessas duas regiões, no Norte há uma homogeneidade grande, com taxas altíssimas, na maioria dos estados e um Estado, Rondônia, se destaca com taxas de fecundidade bem menores. Talvez a herança migratória dessa região possa explicar parte desse comportamento. Na Região Nordeste ocorre 0 contrário, a homogeneidade é grande entre a maioria dos estados com taxas mais baixas relativamente, mas ainda acima da média nacional, e o Estado do Maranhão, se destaca na região com taxa muito elevada (ao redor de 150 por mil).

Também vale mencionar os casos da área rural dos Estados do Acre, Roraima e Amapá, aonde a fecundidade de adolescentes e jovens chega a valores de mais de 180 nascidos vivos por mil mulheres. Vale lembrar que esses estados apresentam populações com migração elevada e também estão entre os estados mais pobres do País.

\section{Diferenciais na fecundidadepor idade simples das mulheres}

Um aspecto importante a ser avaliado, citado no início deste texto, é que as mulheres jovens apresentam heterogeneidade de comportamento internamente ao grupo etário. Considerando somente as mulheres de 15-19 anos é possível observar no Gráfico 5 que a distribuição dos filhos por idade simples das mães está mudando nas últimas décadas, com um peso relativo cada vez maior para as muito jovens (15-17 anos) e diminuição do peso relativo para as mulheres de 18-19 anos, ou seja, um rejuvenescimento dos nascimentos por idade das mulheres. Em 2010, mais de 55\% dos nascimentos ocorrem para mulheres de 18-19 anos e em 1991 este percentual era de $63 \%$. Este fato pode se dar por um aumento relativo maior no número de mulheres mais jovens (e consequentemente maior natalidade) ou por uma variação 
Gráfico 5 Brasil: Distribuição dos filhos nascidos vivos no último ano por idade simples das mães e taxas de fecundidade 1991,2000 e 2010
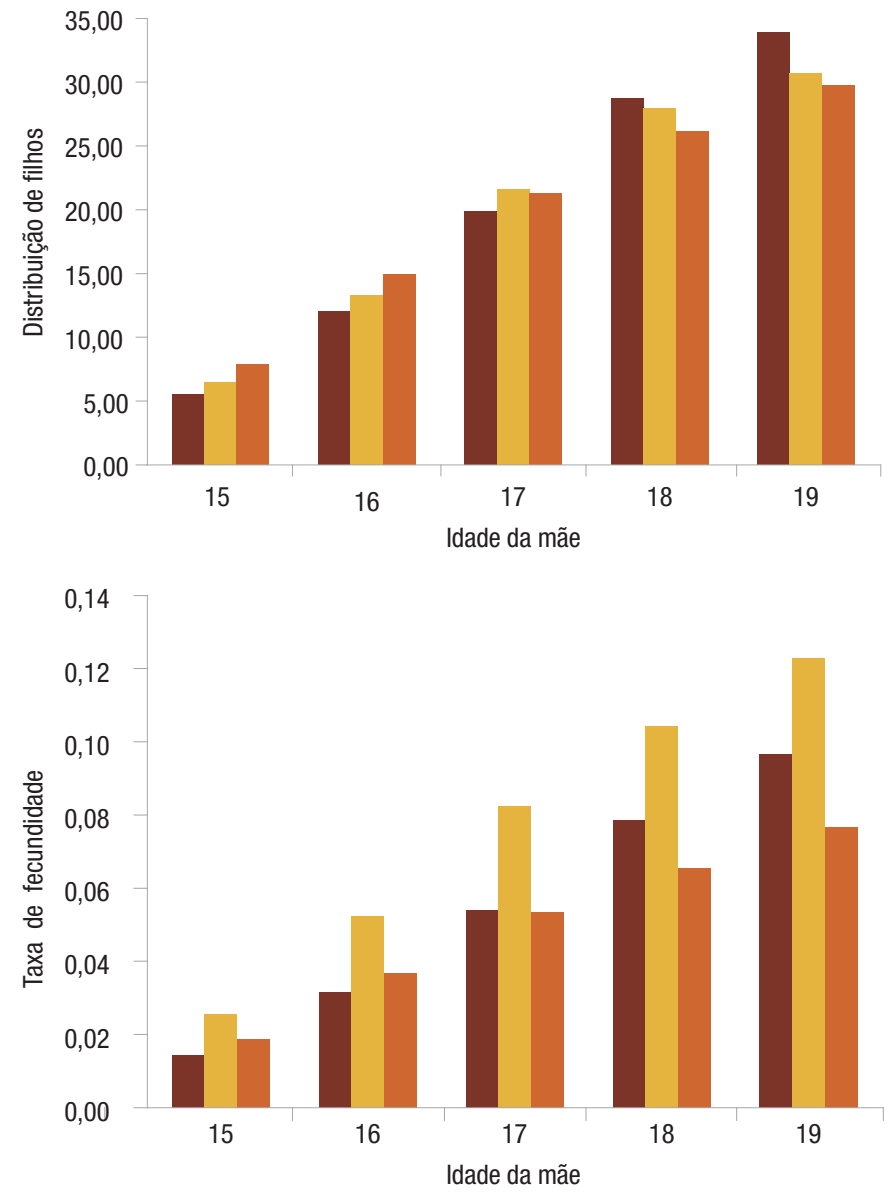

relativa maior da fecundidade das mais jovens em comparação com aquelas de 18-19 anos de idade.

A taxa de fecundidade por idade simples, calculada a partir dos dados censitários, apesar de apresentar problemas de subestimação, pode dar uma ideia melhor do que tem ocorrido com a fecundidade interna ao grupo de 15-19 anos de idade. 0 segundo painel do Gráfico 5 apresenta o número de filhos nascidos no último ano dividido pelo número de mulheres na respectiva idade. Observa-se claramente que 
Gráfico 6 Brasil: Distribuição dos filhos nascidos vivos no último ano por idade simples das mães, segundo as Grandes Regiões, 2010

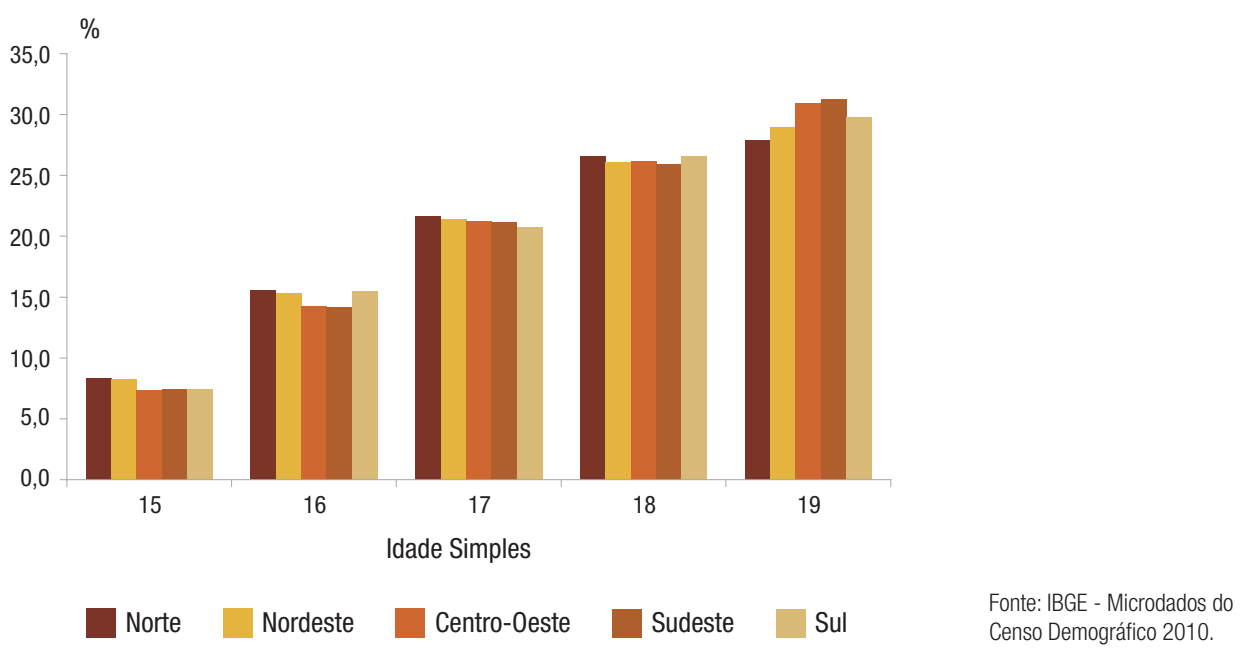

a fecundidade em 2000 aumentou para todas as jovens, mas 0 aumento relativo foi maior entre aquelas no limite inferior do grupo etário, onde o nível de fecundidade era mais baixo. Na década seguinte, todas as jovens apresentaram declínio da fecundidade, no entanto, as mais jovens, principalmente as de 15 e 16 anos de idade, tiveram as menores reduções. Assim, apesar de ainda existir uma heterogeneidade interna ao grupo, esta diminuiu ao longo dos últimos anos.

Interessante notar que a distribuição do número de filhos nascidos vivos por idade simples das mães não apresenta um diferencial regional forte no ano de 2010 (Gráfico 6). Pouco mais de $55 \%$ da fecundidade de jovens é de mulheres de 18 ou 19 anos e 0 restante de mulheres de 15-17 anos. Notável que para todas as regiões, a idade de 17 anos é a que concentra $1 / 5$ de todos os nascimentos, mas de fato, a cada ano de vida, a porcentagem de nascimentos na idade praticamente dobra de valor entre as idades de 15 e 17 anos de idade.

\section{Disparidades nos diferenciais socioeconômicos da fecundidade de 15-19 anos}

A discussão que se dá na literatura sobre 0 comportamento de jovens pode ser revelado pelas desigualdades regionais, mas alguns podem alegar que estas são o resultado de diferenciais culturais e não propriamente econômicos. Afirmam, não 
raras vezes na literatura, que se as mulheres/casais tivessem recursos financeiros poderiam desejar mais filhos e não se teria a fecundidade tão baixa no País. Para a fecundidade de adolescente, pode-se dizer o contrário. As taxas vistas até o momento apontam para taxas de fecundidade muito mais altas em regiões menos desenvolvidas, ou seja, as mulheres com maiores recursos financeiros não optam por maior número de filhos, dado que existem muitos outros constrangimentos para o exercício da maternidade, para além do econômico. Para captar o comportamento econômico com relação ao exercício da maternidade entre mulheres adolescentes e jovens no Brasil, a Tabela 2 apresenta as taxas de fecundidade para mulheres de 15-19 anos,

Tabela 2 Taxas específicas de fecundidade (por 1000 ) de mulheres de 15-19 anos de idade, por situação de domicílio e educação, segundo o rendimento médio mensal domiciliar per capita - Brasil, 2010

\begin{tabular}{|c|c|c|c|c|c|c|c|c|}
\hline \multirow{2}{*}{$\begin{array}{l}\text { Situação de domicílio } \\
\text { e Instrução }\end{array}$} & \multicolumn{8}{|c|}{ Rendimento médio domiciliar per capita em salário mínimo } \\
\hline & Até $1 / 4$ & $>0,25-1 / 2$ & $>1 / 2-1$ & $>1-2$ & $>2-3$ & $>3-5$ & $>5$ & Total \\
\hline Total & 126,6 & 108,8 & 65,5 & 30,6 & 16,4 & 10,5 & 7,6 & 69,9 \\
\hline $\begin{array}{l}\text { Sem instrução e fundamental } \\
\text { incompleto }\end{array}$ & 182,6 & 162,7 & 115,7 & 71,4 & 53,4 & 33,5 & 29,5 & 145,9 \\
\hline $\begin{array}{l}\text { Fundamental completo e } \\
\text { médio incompleto }\end{array}$ & 100,3 & 100,5 & 70,9 & 38,8 & 22,4 & 16,0 & 13,9 & 72,4 \\
\hline $\begin{array}{l}\text { Médio completo e superior } \\
\text { incompleto }\end{array}$ & 54,8 & 65,3 & 45,1 & 23,8 & 13,8 & 9,6 & 8,0 & 35,8 \\
\hline Rural & 134,8 & 107,3 & 68,2 & 37,1 & 32,4 & 24,7 & 25,8 & 103,6 \\
\hline $\begin{array}{l}\text { Sem instrução e fundamental } \\
\text { incompleto }\end{array}$ & 180,5 & 156,5 & 110,6 & 80,9 & 106,3 & 44,7 & 90,1 & 160,3 \\
\hline $\begin{array}{l}\text { Fundamental completo e } \\
\text { médio incompleto }\end{array}$ & 95,1 & 89,9 & 67,1 & 44,1 & 32,8 & 33,9 & 46,5 & 82,3 \\
\hline $\begin{array}{l}\text { Médio completo e superior } \\
\text { incompleto }\end{array}$ & 55,4 & 54,3 & 39,9 & 23,3 & 17,2 & 15,4 & 11,4 & 43,9 \\
\hline Urbano & 122,0 & 109,3 & 65,2 & 30,3 & 15,8 & 10,2 & 7,2 & 64,2 \\
\hline $\begin{array}{l}\text { Sem instrução e fundamental } \\
\text { incompleto }\end{array}$ & 183,9 & 164,8 & 116,6 & 70,5 & 49,2 & 32,8 & 26,7 & 140,7 \\
\hline $\begin{array}{l}\text { Fundamental completo e } \\
\text { médio incompleto }\end{array}$ & 103,0 & 103,1 & 71,3 & 38,5 & 21,9 & 15,3 & 12,9 & 70,6 \\
\hline $\begin{array}{l}\text { Médio completo e superior } \\
\text { incompleto }\end{array}$ & 54,4 & 67,5 & 45,6 & 23,8 & 13,7 & 9,5 & 7,9 & 34,9 \\
\hline
\end{tabular}

Fonte: IBGE - Microdados do Censo Demográfico 2010. 
levando-se em consideração a educação $0^{8}$ e 0 nível sócio econômico em faixas de rendimento médio domiciliar mensal per capita, separando ainda as informações para as áreas urbanas e rurais.

0s dados da Tabela 2 revelam que a categoria de menor renda e menor instrução, como era de se esperar, é aquela onde as mulheres têm maior fecundidade, e em um nível que chega a 10 vezes mais do que aquelas que estão nas categorias mais altas de renda e instrução. Uma jovem que não tem instrução ou tem até 0 ensino fundamental completo e reside em um domicílio com rendimento de até $1 / 4$ do salário mínimo (S.M.) per capita, apresenta fecundidade de mais de 182 nascidos vivos por mil mulheres e, na área urbana, ao contrário do que se esperaria é ainda maior que na área rural, chegando a quase 185 por mil.

Importante notar que ter o ensino médio completo ou superior incompleto não basta para que a fecundidade de jovens seja baixa, em níveis comparáveis aos dos países desenvolvidos. Na área urbana, esta fecundidade é de ao redor 35 por mil e área rural de 44 por mil, mas 0 diferencial por faixa de renda é bastante grande. Para ter fecundidade muito baixa, uma mulher com este nível de instrução mencionado precisa também ter pelo menos cinco ou mais salários mínimos de renda domiciliar per capita.

Um resultado não esperado, observado na Tabela 2, é que as jovens da área urbana de renda baixa (até um salário mínimo per capita) em todas as categorias de instrução apresentam fecundidade um pouco maior que suas contrapartes residentes na área rural. Este resultado pode, em parte, se dever ao fato que na área urbana pode haver uma liberdade sexual maior, assim como maior frequência de atividade sexual e, entre as mulheres com baixa renda, com uso de contracepção mais baixo. De fato, na década de 1990 o crescimento da fecundidade de jovens foi maior na área urbana que na área rural e isto pode ainda estar refletindo na taxa encontrada em 2010.

\section{Exercício da maternidade: dados recentes}

Estudos sobre transição para a vida adulta colocam a maternidade como um evento importante, onde a mulher passa do período da adolescência para a fase adulta. Indicadores sobre 0 exercício da maternidade apontam para questões de políticas públicas muito importantes, que vão mais além da análise das tendências e diferenciais sobre as taxas de fecundidade. No Brasil, segundo os dados de 2010, existe ao

\footnotetext{
${ }^{8}$ Os grupos educacionais apresentados não são de fato os melhores para obter os diferenciais de fecundidade, mas no Censo 2010 não foi possível ainda estimar os anos de estudo e outras faixas de instrução, dado que o censo não incluiu a última série e grau concluídos com aprovação para pessoas que não frequentavam a escola ou creche no período de referência do Censo. No entanto, os agrupamentos disponibilizados mostram diferenciais importantes.
} 


\section{Gráfico 7 Brasil: Porcentagem de mulheres que são mães por idade simples, 2010.}

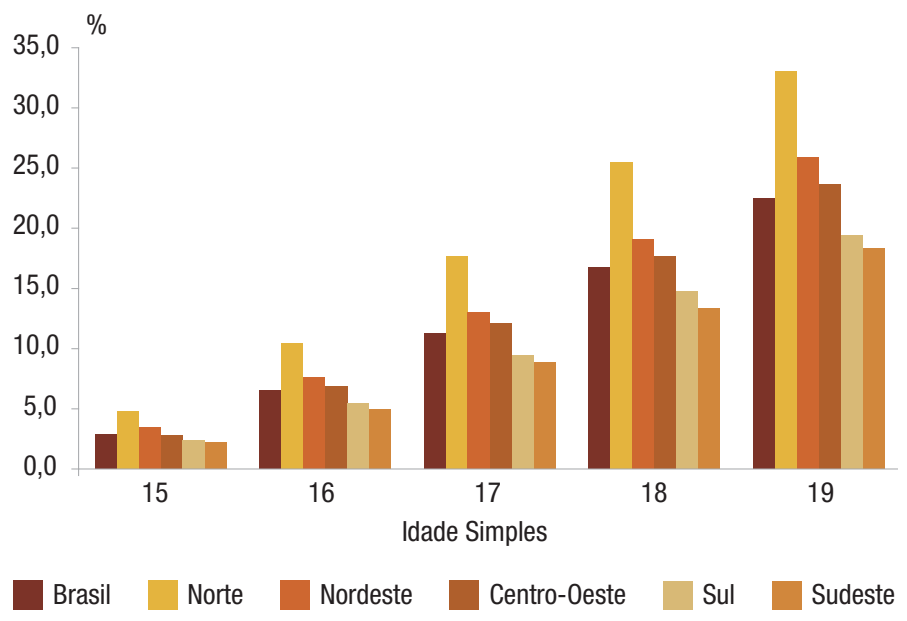

redor de 12\% das mulheres de 15-19 anos que já exerceram a maternidade, tiveram pelo menos um filho nascido vivo e, portanto, foram levadas para a vida adulta pelo exercício da maternidade. Em geral, a maioria das mães nesta idade está fora da escola, segundo Cavenaghi e Berquó (2005), uma mãe nesta idade tem 60 vezes menos chance de estar na escola do que uma menina/mulher que ainda não se tornou mãe.

A porcentagem de mães (Gráfico 7) não está uniformemente distribuída nas idades entre 15 e 19 anos. Do total das meninas de 15 anos, ao redor de $3 \%$ delas eram mães nesta idade no País, chegando a 5\% na Região Norte. Na idade seguinte estes valores dobram e na Região Norte, 10,4\% das meninas de 16 anos já se tornaram mães. Na idade de 17 anos este valor dobra novamente e, ao chegar aos 19 anos, mais de $1 / 5$ das mulheres desta idade já se tornaram mães no Brasil e, novamente, na região mais pobre, elas são 33\% do total das mulheres de 19 anos.

Para o grupo mais jovem, este comportamento pode ser confirmado em 2010, pois entre esses $12 \%$ de mães de $15-19$ anos de idade, mais de $80 \%$ delas teve apenas um filho. Em geral, o primeiro filho chega antes do início do uso de contracepção, mas depois do primeiro nascimento, que em geral não foi planejado, a mulher começa a usar algum método contraceptivo moderno (CAVENAGHI; ALVES, 2011). Assim, 0 uso de contracepção moderna de maneira adequada em um contexto de maior igualdade de gênero é essencial para que uma política de redução da gravidez indesejada tenha sucesso. 


\section{0 exercício da maternidade em diferentes escalas regionais}

Apesar dos diferenciais encontrados regionalmente, sabe-se que as médias regionais podem esconder características importantes, principalmente em um País de grandes dimensões territoriais. Por este motivo, adicionalmente, apresenta-se um pequeno exercício com os dados georreferenciados sobre o exercício da maternidade para mostrar a importância da análise desagregada, em níveis geográficos menores, vinculada a políticas públicas e programas que buscam melhor acesso à saúde reprodutiva e ao cumprimento dos direitos reprodutivos estabelecidos no Programa de Ação da Conferência de População e Desenvolvimento de 1994.

Ainda que programas e ações em nível nacional são importantes para dar acesso adequado aos direitos reprodutivos, ações localizadas são essenciais para obter-se sucesso nos objetivos colocados, principalmente quando o evento em ques-

MAPA 1 Brasil: Porcentagem de mulheres de 15-19 anos que são mães segundo as mesorregiões, 2010

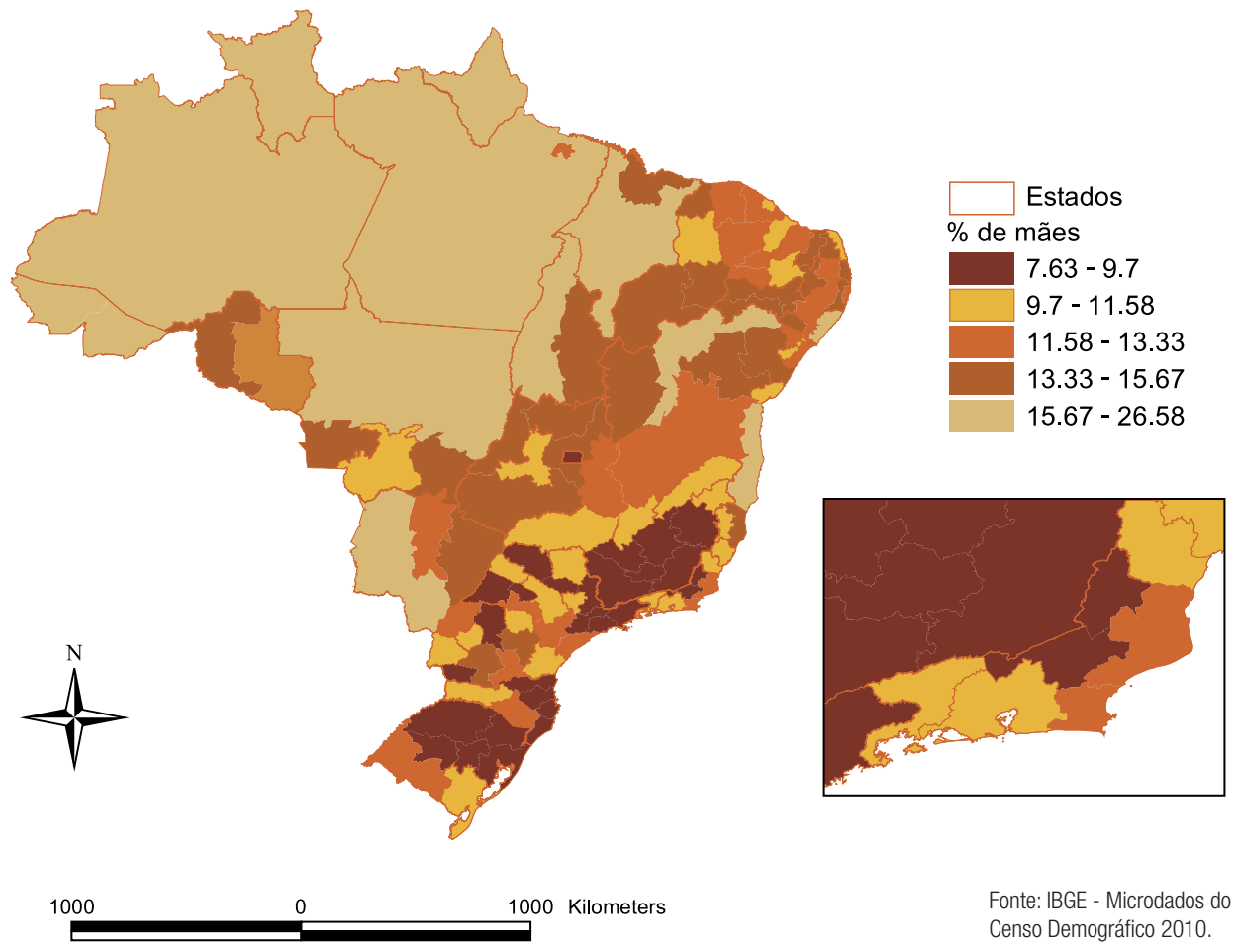


tão apresenta diferenciais regionais tão importantes quanto os que foram vistos para 0 caso da fecundidade entre adolescentes e jovens. A identificação da localização geográfica do público objetivo destas ações torna-se crucial desde diagnóstico e desenho até a implementação da política pública ou ação programática específica. Nesta subseção, busca-se mostrar um pequeno estudo de caso de como 0 conhecimento detalhado da região é importante para caracterizar ou, ao pé da letra, mapear a situação desejada. A porcentagem de mulheres jovens que tiveram pelo menos um filho entre todas as mulheres é de $12 \%$ para o País, mas varia de $7,6 \%$ a $26,6 \%$ se a área geográfica considerada for a mesorregião (Mapa 1). A Região Norte, parte do norte da Região Centro-Oeste e algumas áreas da Região Nordeste (quase todo Estado do Maranhão e oeste do Estado da Bahia) são as áreas onde a porcentagem de adolescentes e mães é mais alta que a média nacional. Internamente em cada estado das regiões Nordeste, Sudeste e Sul apresentam variações importantes neste indicador. Olhando mais de perto 0 que acontece com estes padrões espaciais, pode-se verificar que 0 Estado do Rio de Janeiro apresenta três padrões distintos de exercício da maternidade, se forem consideradas as mesorregiões. No entanto, como se verá nos Mapas 2 e 3, quando maior a desagregação geográfica, melhor se pode localizar as áreas onde a questão da fecundidade de adolescentes e jovens pode ser considerada mais intensa.

Os padrões que aparecem no Mapa 2, que divide o País em 537 áreas (microrregiões), confirmam 0 argumento de que 0 detalhamento geográfico permite descrever melhor a situação em estudo, pois mostra que a porcentagem de mães jovens é alta em regiões mais desenvolvidas e, ao mesmo tempo, há várias áreas em regiões menos desenvolvidas com baixa porcentagem de mães jovens. Conhecendo as demais informações da área, ou refinando mais a escala geográfica, ajuda a desenhar melhor políticas públicas que sejam dirigidas ao exercício pleno dos direitos sexuais e reprodutivos. Observa-se no Mapa 2 que quando se trata de microrregiões, a porcentagem mínima e máxima se alteram significantemente, variando de ao redor de $5 \%$ até quase $30 \%$. Esta porcentagem máxima, de fato, é 0 valor mais alto observado para mulheres de 19 anos de idade residentes na Região Norte, como observado anteriormente (Gráfico 9).

0 destaque do Rio de Janeiro no Mapa 2 mostra que com o nível de detalhamento de microrregiões quatro dos cinco diferentes intervalos de porcentagem de mães aparecem no estado, identificando melhor as áreas com baixa e alta porcentagem de mulheres jovens que são mães. Verifica-se também que a maioria dos estados da Região Centro-Oeste e 0 Estado do Paraná apresentam regiões com altíssima porcentagem de mães jovens. Adicionalmente, conhecer melhor os dados socioeconômicos destas áreas poderia trazer resultados positivos no desenho de uma política direcionada a reduzir a gravidez não planejada. 
As duas unidades anteriores, meso e microregiões, são agregações de Municípios que não têm organização administrativa, neste sentido, os Municípios são unidades geográficas que são importantes para a tomada de decisões e aplicação de políticas locais. 0 Mapa 3 mostra a distribuição espacial da porcentagem de mães de 15-19 anos de idade em nível municipal. Nesta escala geográfica, não somente existem unidades que não tiveram nenhum nascimento de filhos de mulheres jovens como alguns que tiveram quase $40 \%$ das mulheres nesta mesma faixa etária que já são mães. De fato, para identificar melhor a distribuição, foi necessário aumentar um intervalo que inclui as porcentagens de 30 ou mais e, as unidades nesta categoria estão localizadas, principalmente, na Região Norte do País, mas também aparecem Municípios nesta categoria mais alta em vários estados da Região Nordeste e alguns Municípios do Sudeste, nos Estados de Minas Gerais e São Paulo. 0 Estado do Rio de Janeiro, mostrado na área

MAPA 2 Brasil: Porcentagem de mulheres de 15-19 anos que são mães segundo microrregiões, 2010
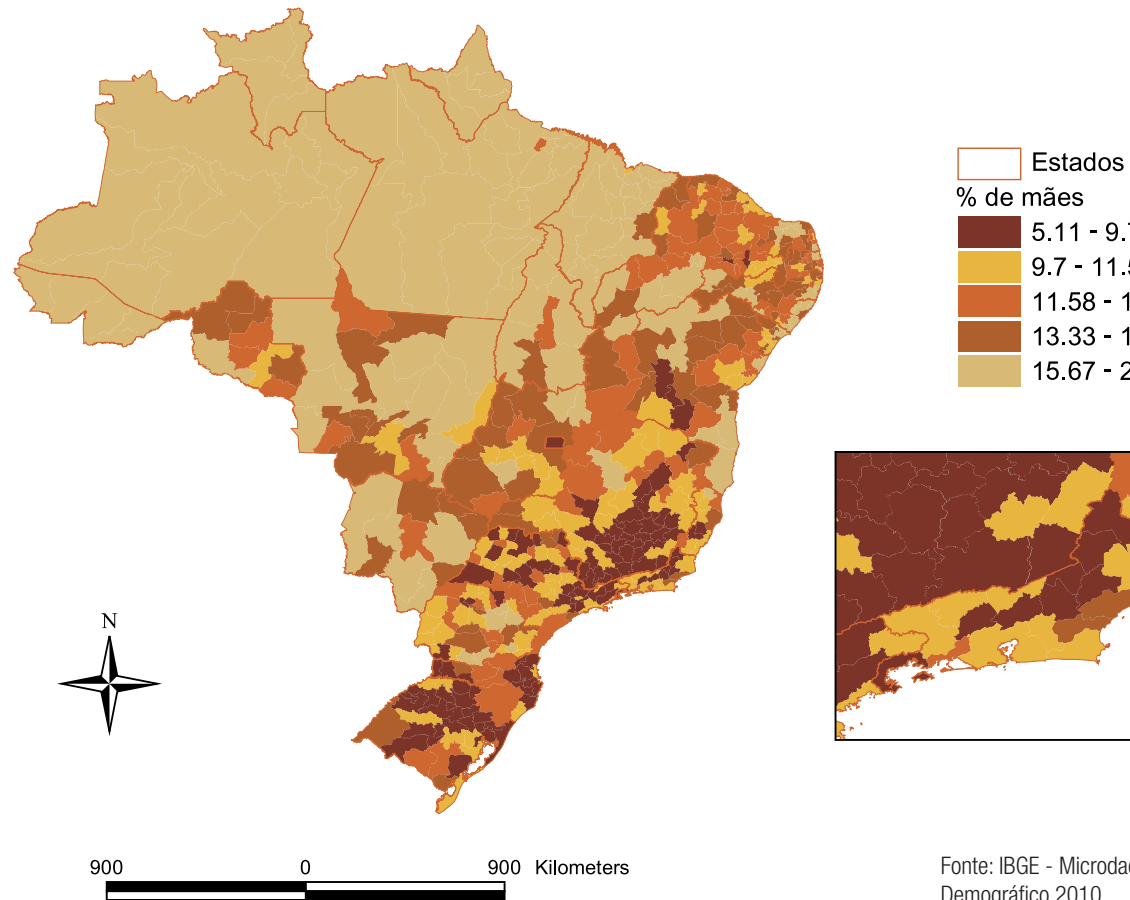
$\%$ de mães

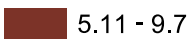
$9.7-11.58$ $11.58-13.33$ $13.33-15.67$ $15.67-29.2$

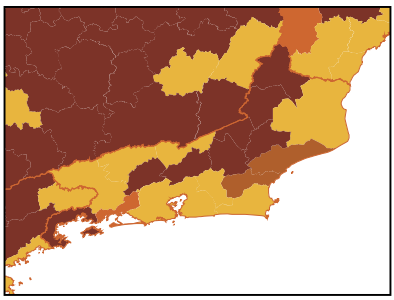

Fonte: IBGE - Microdados do Censo Demográfico 2010. 
MAPA 3 Brasil: Porcentagem de mulheres de 15-19 anos que são mães segundo os municípios, 2010
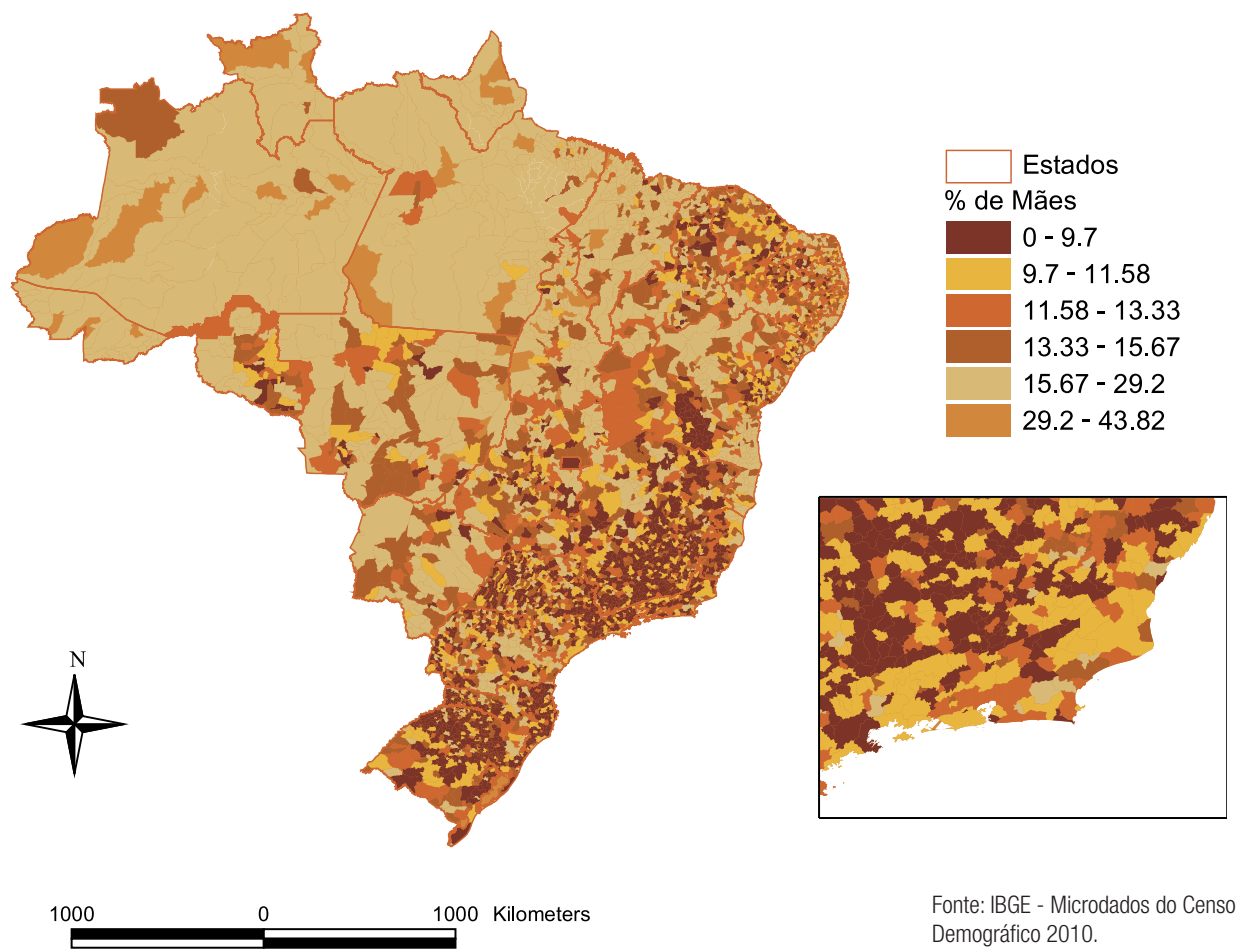

$29.2-43.82$

Fonte: IBGE - Microdados do Censo Demográfico 2010

com maior detalhamento do mapa não apresenta nenhum Município na categoria de porcentagem mais alta de mães, mas mostra alguns Municípios no intervalo de $15 \%$ a $29,2 \%$ de mães, diferente do mostrado nas escalas anteriores.

\section{Panorama recente da saúde reprodutiva das ado- lescentes e jovens segundo diferenciais regionais}

0 panorama diferencial da fecundidade está relacionado com os diferenciais regionais no acesso à saúde reprodutiva, que ainda são grandes e é importante identificá-los para que as ações nesta área sejam mais efetivas. Esta seção tem o propósito de mostrar quais são os diferenciais regionais a partir de algumas temáticas 
específicas como atividade sexual, contracepção e acesso ao pré-natal com alguns indicadores de qualidade deste acesso, a partir de marcadores como a realização de exame de sangue e vacina antitetânica.

\section{Dados e métodos}

Dados mais recentes seriam necessários para esta análise, mas para o Brasil, os dados mais recentes estão disponíveis na PNDS 2006. Esta pesquisa foi realizada nos moldes das pesquisas de demografia e saúde (DHS), com algumas especificidades para 0 caso brasileiro, com entrevistas feitas com as mulheres de 15 a 40 anos de idade residentes nos domicílios selecionados. A amostra foi coletada com representatividade regional e para as áreas urbana e rural, com base em uma seleção de setores censitários do ano de 2000 e atualizados no ano de 2006. Para detalhes metodológicos da PNDS, pode-se consultar Cavenaghi (2009a).

Com relação às variáveis selecionadas, deve-se mencionar algumas escolhas que foram feitas, visto que estas são coletadas em diferentes seções do questionários da PNDS. Para o indicador sobre exercício da maternidade, utilizou-se a variável sobre número de filhos tidos nascidos vivos, considerando como mães aquelas que tinham pelo menos um filho nascido vivo. Para a análise da atividade sexual, selecionou-se as mulheres que declararam ter tido alguma atividade sexual na vida, ainda que não estivessem sexualmente ativas no momento da entrevista, a partir da pergunta sobre a idade da primeira relação sexual. A pergunta sobre gravidez atual é obtida logo no começo da entrevista, na seção sobre reprodução, assim como a informação sobre o planejamento da gravidez atual ${ }^{9}$. Para as informações sobre primeiros eventos, buscou-se relacionar aqueles que pudessem dar uma ideia da ordem em que os fatos ocorrem em média na vida das jovens após a primeira relação sexual. Assim, os indicadores usados foram de idade média à primeira relação sexual, idade média no uso do primeiro método contraceptivo, idade média na primeira gravidez $\mathrm{e}$ idade média à primeira união.

Para a análise sobre saúde reprodutiva, selecionou-se alguns indicadores que pudessem dar um panorama sobre a situação das jovens com relação à prevenção da gravidez e indicadores de acesso a alguns serviços essenciais durante a gravidez. Os indicadores selecionados foram o uso atual de contracepção, e a realização de alguns

\footnotetext{
${ }^{9} \mathrm{~A}$ pergunta sobre planejamento da gravidez está disponível para todos os filhos nascidos nos cinco anos anteriores à data da pesquisa, mas selecionou-se que a gravidez atual, dado que está dá um melhor indicativo sobre a situação mais recente. A pergunta utilizada foi "Quando ficou grávida, estava querendo engravidar naquele momento, queria esperar mais, ou não queria ter (mais) filhos?"
} 
procedimentos na gravidez corrente, como 0 exame pré-natal, exame de sangue e vacina antitétano.

\section{Atividade sexual, gravidez e maternidade}

Devido às altas taxas de fecundidade do passado, 0 grupo populacional de $15 \mathrm{a}$ 19 anos de idade no Brasil é um dos maiores grupos. Em 2006, eram estimadas mais de 8,5 milhões de mulheres neste grupo etário. Por este motivo, apesar de alta a fecundidade das mulheres neste grupo etário, o percentual de mulheres que são mães às vezes não é considerado tão alto, no entanto, são mais de 1,3 milhão de mulheres, dado que em 2006 mais de 16\% das mulheres declararam ter pelo menos um filho (Tabela 3). Este indicador, no entanto, pode ser melhor apreciado se calculado para as mulheres que declararam ter tido relações sexuais, que são $55,1 \%$ das mulheres entre 15-19 anos. Entre aquelas que já tiveram relações sexuais, $29,3 \%$ tiveram pelo menos um filho nascido vivo e $12,5 \%$ estavam grávidas no momento da pesquisa. Quanto ao número de filhos, a grande maioria destas tinha somente um filho.

Importante notar que na área rural, apesar de a atividade sexual se dar em porcentagem muito parecida à da área urbana, a realização da maternidade é bem mais alta na área rural, onde $38,3 \%$ das mulheres sexualmente ativas que moravam na área rural eram mães e 10,6\% estavam grávidas no momento da pesquisa. Parte da explicação desses fatos está em que na área rural a formação de famílias ainda em idade jovem é um padrão mais comum, dando poucas oportunidades distintas a

Tabela 3 Brasil: Indicadores sobre maternidade e atividade sexual de mulheres de 15-19 anos, segundo as Grandes Regiões e a área de residência - 2006

\begin{tabular}{|c|c|c|c|c|c|c|c|c|}
\hline \multirow{2}{*}{ Indicadores selecionados } & \multicolumn{5}{|c|}{ Grandes Regiões } & \multicolumn{2}{|c|}{$\begin{array}{l}\text { Área de } \\
\text { residência }\end{array}$} & \multirow{2}{*}{ Total } \\
\hline & Norte & Nordeste & $\begin{array}{l}\text { Centro- } \\
\text { Oeste }\end{array}$ & Sudeste & Sul & Urbano & Rural & \\
\hline Percentual de mães no total & 23,9 & 16,9 & 13,7 & 14,4 & 20,5 & 15,0 & 21,4 & 16,1 \\
\hline Percentual de sexualmente ativas & 67,2 & 49,5 & 55,1 & 59,6 & 55,9 & 55,0 & 55,9 & 55,1 \\
\hline $\begin{array}{l}\text { Percentual mães entre as sexualmen- } \\
\text { te ativas }\end{array}$ & 35,6 & 34,2 & 24,9 & 24,1 & 36,7 & 27,2 & 38,3 & 29,3 \\
\hline Com 1 filho & 27,0 & 27,2 & 23,9 & 20,3 & 34,3 & 23,9 & 31,7 & 25,3 \\
\hline Com 2 filhos ou mais & 8,6 & 7,0 & 0,9 & 3,9 & 2,4 & 3,4 & 6,5 & 4,0 \\
\hline $\begin{array}{l}\text { Percentual grávidas (entre sexual- } \\
\text { mente ativas) }\end{array}$ & 16,8 & 8,9 & 14,7 & 10,3 & 12,0 & 12,9 & 10,6 & 12,5 \\
\hline
\end{tabular}

Fonte: PNDS, 2006. 
esta para as mulheres. Interessante observar também que em 2006, apesar de o percentual de mães na área urbana ser menor que na rural, o percentual daquelas que estavam atualmente grávidas era maior na área urbana, provavelmente ainda efeito do maior aumento da fecundidade de jovens em áreas urbanas na década anterior.

A análise por Grandes Regiões (Tabela 3) revela as mesmas características da análise por área de residência. Há de fato um diferencial regional ainda bastante acentuado no exercício da maternidade, com as regiões mais desenvolvidas com as menores porcentagens. Quanto à atividade sexual, o diferencial é menor, no entanto, na Região Norte, onde há ainda populações com tradições indígenas e também populações rurais e urbanas muito pobres, a porcentagem de atividade sexual chega a mais de $67 \%$ das jovens. A Região Centro-0este chama atenção, pois apresenta taxas mais altas que a Região Nordeste, para a maternidade, entre 0 total de mulheres e entre as sexualmente ativas, mas apresenta atividade sexual nos mesmo níveis que as regiões mais desenvolvidas. 0 Nordeste, por outro lado, apesar de apresentar percentual de atividade sexual abaixo da média, apresenta alto percentual de mães entre as sexualmente ativas. Este resultado chama atenção para o fato que a maternidade entre mulheres de 15 a 19 anos ocorre em duas situações, aquelas mencionadas no início, por comportamentos ainda tradicionais, com formação precoce de família e outra em decorrência de maior prática sexual devido à maior liberdade sexual.

Com relação ao número de filhos, na Região Norte, seguida pela Região Nordeste, a prática de ter o segundo filho (ou mais) é bem mais frequente, em mais de $1 / 3$ dos casos. 0 contrário se passa nas Regiões Sudeste e Centro-Oeste, onde parece que 0 primeiro filho quiçá não planejado teve ocorrência. A identificação dessas mulheres com comportamentos distintos é importante, dado que qualquer ação no sentido de assegurar acesso aos direitos reprodutivos delas passa necessariamente por programas e ações distintas.

\section{Idade à iniciação em eventos selecionados e relacionados com a maternidade}

A sequência de eventos desde a primeira relação sexual até a primeira gravidez poderiam parecer eventos bem marcados em diferentes idades das mulheres. Em nossa sociedade, o casamento ou união é um evento que, em geral, ocorre com frequência, principalmente se tem gravidez ou nascimento envolvidos. Na Tabela 4 pode-se observar as idades médias de ocorrência de uma série de eventos selecionados para as mulheres que já completaram 19 anos: primeira relação sexual, uso do primeiro método contraceptivo, primeira gravidez, primeira união (legal ou consensual) e nascimento do primeiro filho. Visto que o grupo de mulheres em análise é de jovens 
Tabela 4 Brasil: indicadores de iniciação em eventos selecionados (idade média) para mulheres de 19 anos de idade por regiões e área de residência - 2006

\begin{tabular}{|lcccccccc}
\hline Idades médias & Norte & Nordeste & $\begin{array}{c}\text { Centro- } \\
\text { Oeste }\end{array}$ & Sudeste & Sul & Urbano & Rural & Total \\
\hline Primeira relação sexual & 15,6 & 15,3 & 16,1 & 15,7 & 15,9 & 15,8 & 15,2 & 15,7 \\
\hline Primeiro método & 16,0 & 15,8 & 16,2 & 15,8 & 16,2 & 16,1 & 15,7 & 16,0 \\
\hline Primeira gravidez & 16,3 & 16,2 & 16,5 & 15,9 & 17,0 & 16,5 & 15,8 & 16,3 \\
\hline Primeira união & 16,6 & 16,6 & 16,6 & 16,3 & 16,9 & 16,9 & 16,0 & 16,6 \\
\hline Primeiro filho & 16,8 & 16,9 & 17,2 & 16,8 & 17,9 & 17,3 & 16,5 & 17,0 \\
\hline Porcentagem de mulheres de 19 anos de idade com ocorrência dos eventos & & & & \\
\hline Tiveram relação sexual & 86,4 & 74,9 & 78,3 & 84,2 & 74,6 & 78,2 & 79,4 & 78,5 \\
\hline Usaram algum método entre ativas & 97,2 & 95,3 & 91,2 & 100,0 & 97,0 & 96,2 & 92,5 & 95,3 \\
\hline Ficaram grávidas entre ativas & 68,3 & 60,9 & 42,7 & 64,1 & 67,4 & 52,2 & 73,1 & 57,4 \\
\hline Estiveram em união entre ativas & 53,1 & 59,3 & 29,2 & 41,9 & 50,3 & 42,4 & 56,9 & 46,0 \\
\hline Tiveram filho nascido vivo entre ativas & 47,1 & 50,1 & 29,0 & 41,8 & 46,3 & 38,7 & 51,1 & 41,7
\end{tabular}

Fonte: PNDS, 2006

e muitas não tiveram algum dos eventos analisados, assim, não contribuiriam para a média de idade de ocorrência dos eventos, apresenta-se na parte inferior da Tabela 4 a porcentegam de mulheres de 19 anos de idade que experienciaram estes eventos.

Observa-se que, no Brasil, a iniciação sexual para mulheres nesta idade em 2006, ou seja, aquelas nascidas em 1987, era alta, visto que quase $80 \%$ delas já tinham se inciado sexualmente, $57,4 \%$ destas com iniciação sexual tinham ficado grávidas e 41,7\% tinham tido pelo menos um filho nascido vivo. Interessante observar que, apesar da dificuldade em se relatar sobre a ocorrência de interrupção da gravidez, voluntária ou não, nem toda gravidez terminou em nascido vivo. Da mesma forma, chama atenção que mais de $95 \%$ das sexualmente ativas declararam ter usado método contraceptivo, mas pela idade média de iniciação sexual e idade média de primero uso de método pode-se inferir que para a maioria dessas mulheres o uso do método ocorreu somente após a iniciação sexual ${ }^{10}$. A análise dos dados regionais apontam na mesma direção, em algumas regiões e no rural com incidência maior

\footnotetext{
${ }^{10} \mathrm{~A}$ informação ideal para este tipo de análise seria o uso do calendário contraceptivo que, em geral, é coletado nas pesquisas de Demografia e Saúde. No entanto, na PNDS 2006 esta informação não foi coletada devido à alta complexidade do questionário e ao problema de memória que esta informação tem. No entanto, para mulheres mais jovens, com o objetivo de conhecer realmente as práticas para os diversos seguimentos populacionais, seria importante coletar esta informação em pesquisas futuras.
} 
de iniciação sexual e gravidez, no entanto, não há uma relação clara entre maior incidência desses eventos e nível de desenvolvimento da região.

Com relação às idades médias de ocorrência dos eventos, em primeiro lugar, chama a atenção que as diferenças nas idades médias apresentadas, tanto para os diversos eventos quanto para recortes regionais e área urbana ou rural, são muito pequenas e são todas muito baixas, próximas aos 15 e 16 anos de idade. Em segundo lugar, chama atenção que a sequência de união e depois gravidez, que poderia ser esperada, não acontece na maioria dos lugares analisados, e de fato são idades médias sempre muito próximas. Em terceiro lugar, reafirmando o que foi colocado anteriormente, outra sequência que deveria estar bem marcada é sobre 0 uso de método contraceptivo e primeira relação sexual. Aqui, pode-se observar que a idade média de uso do primeiro método está tão próxima da idade da primeira gravidez quanto da idade da primeira relação sexual e às vezes mais próxima da gravidez. Esta informação é relevante, dado que 0 acesso aos métodos contraceptivos modernos e eficientes para o livre exercício da sexualidade é imprescindível que ocorra juntamente com a iniciação da atividade sexual, não somente para prevenção de gravidez não planejada, mas também para evitar doenças sexualmente transmissíveis. Estes fatos apontam para a necessidade de melhor educação sexual, visto que a declaração sobre conhecimento de métodos contraceptivos para mulheres é bastante alto, chegando a quase $100 \%$.

\section{Diferenciais regionais no uso da contracepção}

A informação sobre contracepção é essencial neste cenário de iniciação sexual em idade jovem. A Tabela 5 mostra a porcentagem de mulheres sexualmente ativas que usam contracepção e o tipo de contraceptivo usado. Verifica-se que o percentual de uso no Brasil para mulheres de 15-19 anos de idade é bastante alto, com 75,9\% para o País, mas chegando a alcançar $81,80 \%$ das mulheres sexualmente ativas na Região Sul. Novamente, o diferencial regional não é desprezível, pois na Região Norte 0 uso fica em menos de $65 \%$. As áreas urbana e rural apresentam diferencial e, como esperado, na área rural o uso é menor, mas, mesmo assim, observa-se que quase $72 \%$ das jovens morando nestas áreas declararam usar algum método contraceptivo. Apesar de ainda ter um percentual alto de jovens que não usam, mesmo porque a maioria das jovens poderiam não estar planejando engravidar, este nível é bem mais alto que em outros países da América Latina (CAVENAGHI, 2009b).

0 leque de contraceptivos usados é bastante pequeno. 0s métodos hormonais são os mais utilizados na área urbana e quase toda as regiões, exceto na Região Norte, onde o preservativo é o metodo mais prevalente. Isto pode ser por questões culturais, mas também pode ser explicado pela provisão do método em uma área tão 
Tabela 5 Brasil: Distribuição da contracepção entre as mulheres sexualmente ativas de 15-19 anos de ídade por regiões e área de residência - 2006

\begin{tabular}{|c|c|c|c|c|c|c|c|c|}
\hline & \multicolumn{5}{|c|}{ Regiões } & \multicolumn{2}{|c|}{ Área de Residência } & \multirow[b]{2}{*}{ Total } \\
\hline & Norte & Nordeste & $\begin{array}{l}\text { Centro- } \\
\text { Oeste }\end{array}$ & Sudeste & Sul & Urbano & Rural & \\
\hline Total que usam & 63,5 & 80,4 & 74,6 & 74,1 & 81,8 & 77,1 & 71,6 & 75,9 \\
\hline Esterilização feminina & 0,0 & 0,0 & 0,4 & 0,1 & 0,0 & 0,0 & 0,3 & 0,1 \\
\hline Esterilização masculina & 0,0 & 0,6 & 0,0 & 0,1 & 0,0 & 0,2 & 0,3 & 0,2 \\
\hline Pílula & 14,9 & 33,4 & 33,0 & 31,4 & 44,6 & 29,2 & 45,9 & 32,2 \\
\hline Pílula do dia seguinte & 0,0 & 0,5 & 0,2 & 0,0 & 0,0 & 0,2 & 0,0 & 0,1 \\
\hline Injetáveis e outros & 5,2 & 5,8 & 6,0 & 8,0 & 2,9 & 7,1 & 2,3 & 6,2 \\
\hline Preservativo & 41,6 & 35,1 & 34,6 & 32,0 & 31,0 & 36,5 & 22,1 & 33,9 \\
\hline Outros & 1,9 & 5,1 & 0,4 & 2,5 & 3,2 & 3,9 & 0,6 & 3,1 \\
\hline Não usam & 36,5 & 19,6 & 25,4 & 25,9 & 18,2 & 22,9 & 28,4 & 24,1 \\
\hline Total & 100,0 & 100,0 & 100,0 & 100,0 & 100,0 & 100,0 & 100,0 & 100,0 \\
\hline
\end{tabular}

Fonte: PNDS, 2006.

vasta como a Amazônia. Entre os métodos hormonais, a pílula é de longe 0 método mais usado em todas as regiões. Em trabalho sobre a América Latina, Cavenaghi (2009b) mostra como a provisão de métodos acaba definindo de alguma maneira 0 mix-contraceptivo nos diversos países e, muito provavelmente isto também acontece regionalmente em um País com as dimensões do Brasil. De fato, neste grupo etário de jovens não seria realmente esperado o uso de esterilização, mas apesar de muito pequeno, este método aparece citado por usuárias em algumas regiões, como Nordeste e Sudeste com a esterilização masculina e no Centro-0este com a esterilização feminina.

0 percentual de mulheres sexualmente ativas que não usam métodos ${ }^{11}$ não poderia explicar toda a falha no planejamento da fecundidade que aparece refletido nos resultados do Gráfico 8, a qual apresenta a informação se a gravidez atual foi desejada para aquele momento, se queriam esperar mais ou se de fato não queriam ter engravidado. 0 que de fato explica os resultados são as altas taxas de falhas no uso dos métodos que, em geral, não têm uso regular e consistente. Observa-se que entre as jovens no Brasil, somente $33 \%$ das mulheres grávidas queriam estar grávidas naquele momento e mais de $57 \%$ queriam ter esperado mais para ter filho. Interessante

${ }^{11}$ Importante mencionar que este indicador considera no denominador todas as mulheres sexualmente ativas, assim, não eliminou as mulheres estéreis e as grávidas no momento da pesquisa e que, portanto, não estão expostas ao risco de engravidar. 
observar que mesmo entre jovens, quase $10 \%$ das mulheres responderam que não queriam ter mais filhos em sua vida. Algumas destas não queriam ter filhos e outras tiveram um ou dois e com isto tinham completado seus planos de maternidade.

A análise deste mesmo indicador (Gráfico 8) para as áreas urbana e ruralmostra que 0 diferencial de comportamento entre essas áreas é grande. Por um lado, na área rural metade $(50,7 \%)$ das mulheres tinham planejado engravidar naquele momento $\mathrm{e}$ a outra metada teve falha na reprodução, se denominamos esta como a porcentagem que queria ter esperado mais tempo (37\%) mais a porcentagem que disse que não queria ter mais filhos quando engravidaram (12,5\%), e este número para as urbanas era $9,4 \%$. Na área urbana a porcentagem de grávidas que disseram ter os filhos no momento errado ou que não queriam mais é muito maior do que na área rural, pois $70 \%$ das mulheres estavam nesta situação, onde $61,5 \%$ engravidaram no tempo não planejado e 8,8\% não queriam ter filhos. Interessante notar que esta "falha reprodutiva" parece ser maior na área urbana, pois apesar de ter maior prevalência no uso de contraceptivos comparado com as jovens que moram na área rural, o exercício da maternidade sem planejamento é maior na área urbana. Isto pode decorrer realmente por falhas contraceptivas maiores por inconsistência no uso na área urbana ou pode ser que a resposta à pergunta sobre planejamento reprodutivo na área rural, no post-facto, como mencionado no início do texto seja maior entre as mulheres que moram no campo.

\section{Gráfico 8 Brasil: Planejamento da gravidez com relação à gravidez atual para mulheres de 15-19 anos de idade por regiões e área de residência}

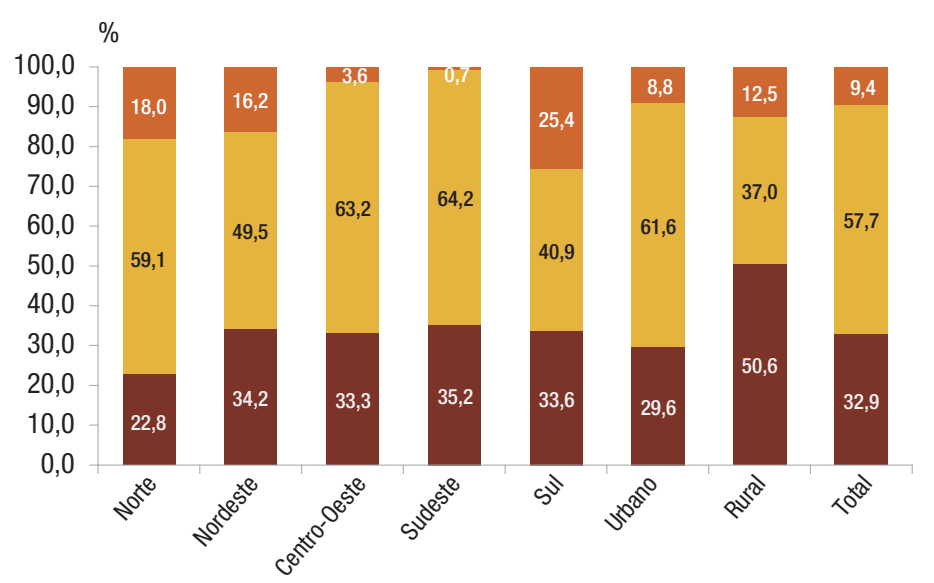

Queria naquele momento

Queria esperar mais

Não queria mais filhos

Fonte: PNDS, 2006. 
Com relação ao comportamento regional sobre o planejamento da gravidez atual não há um padrão típico observado, mas em todas as regiões, exceto no Norte, a porcentagem de "falha reprodutiva" é similar, em torno de $65 \%$. No entanto, as quatro regiões apresentam uma variedade enorme na porcentagem que declarou que não queria ter tido o filho, variando de $25,4 \%$ na Região Sul a menos de $1 \%$ na Região Sudeste (Gráfico 8). A Região Norte é a que se apresenta com o comportamento mais distinto entre todas as regiões, pois apresenta menor porcentagem de mulheres que declararam querer a gravidez naquele momento e, por outro lado, também apresenta alta porcentagem daquelas que já não queriam ter mais filhos. Como se verá mais adiante, a fecundidade de jovens apresenta diferencial grande nestas regiões, como, por exemplo, com a fecundidade na Região Norte mais do que o dobro da Região Sul e em ambas as regiões, a porcentagem de mulheres grávidas de 15-19 anos que declararam não querer ter mais filhos é alta.

Se a vida contraceptiva e o exercício adequado dos direitos sexuais e reprodutivos das jovens brasileiras já não é um exemplo a seguir, a questão do acesso aos serviços adequados de saúde reprodutiva continua colocando em cheque 0 exercício da maternidade. 0 Gráfico 9 apresenta três indicadores que são marcadores importantes sobre a qualidade da atenção pré-natal, a porcentagem de grávidas que

Gráfico 9 Brasil: Indicadores selecionados de qualidade da atenção pré-natal para gravidez atual de mulheres de 15-19 anos de idade por regiões e área de residência

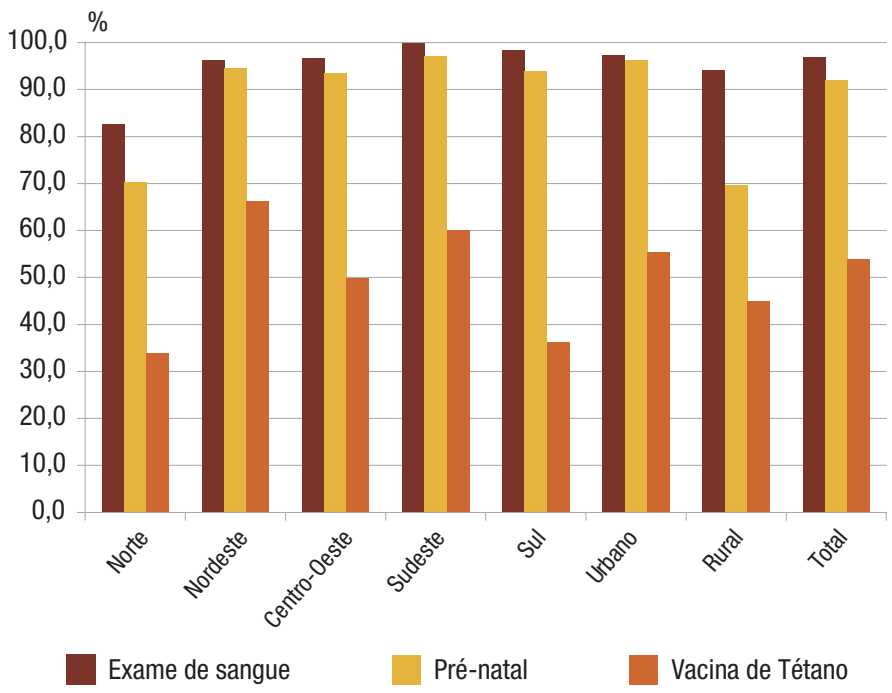


realizaram exame de sangue durante a gravidez, a porcentagem de mulheres que declaram ter feito pré-natal (sem medir a quantidade e qualidade deste) e a porcentagem de mulheres que tomaram vacina antitetânica no início da gravidez. 0 primeiro indicador mostra que 0 exame de sangue é quase universal em todas as regiões, mas a área rural, o Nordeste e, principalmente, a Região Norte têm porcentagem importante de grávidas que não realizaram nenhum exame de sangue, o que parece inconcebível, pois mesmo para a confirmação da gravidez se realiza este tipo de exame.

Quando se analisa a prática do prenatal a situação começa a se delinear como mais problemática ainda na área rural e Região Norte, ao redor de 30\% das gravidas não realizaram exame pré-natal. Mesmo nas regiões mais desenvolvidas esta prática não atinge $0100 \%$ que se esperaria em uma época que o parto é tão medicalizado e o Brasil apresenta um sistema de saúde que se supõe tem acesso universal. A dose de vacina de tétano, além de dar um indicativo sobre 0 acesso à saúde reprodutiva, mas especificamente aponta para a qualidade do pré-natal, dado que em um bom pré-natal, o mínimo que se espera é que a vacina de tétano seja administrada na grávida. No entanto, os dados mostram que tanto na área rural quanto na urbana $\mathrm{e}$ em todas as regiões, este indicador chega em $50 \%$ das gravidezes. Na Região Norte, como se esperaria, e estranhamente na Região Sul, o percentual fica ao redor de $30 \%$. Ou seja, ainda que em mais de $90 \%$ das gravidezes atuais tenha sido se realizado o pré-natal, no total do País, em somente $50 \%$ delas o marcador mais básico de qualidade deste pré-natal, a vacina de tétano, somente foi dada (Gráfico 9). 


\section{Considerações finais}

0 padrão rejuvenescido da fecundidade no Brasil atrelado a regimes baixos de fecundidade tem um impacto grande no mix contraceptivo adotado. Como as mulheres começam a ter filhos em idades jovens, elas atingem 0 tamanho ideal de família também cedo. Assim, com uma idade em torno de 25 anos as muIheres já tiveram os filhos desejados e passam a utilizar uma forma de controle definitivo da fecundidade, isto é, a esterilização. Na maioria dos casos, são as mulheres que fazem a esterilização. Mas tem crescido muito o número de homens que fazem vasectomia. Este padrão de fecundidade precoce e "fechamento da fábrica" é mais comum nas "classes" sociais de mais baixa renda e baixo nível de escolaridade. Nos estratos médios e altos, o padrão tende a ser mais envelhecido, ou seja, as meninas ficam mais tempo na escola, chegam à universidade $\mathrm{e}$ se casam mais tarde. Portanto, o padrão rejuvenescido de fecundidade precoce é diferenciado conforme o nível de renda e escolaridade das famílias brasileiras. 0 que estas mulheres precisam não é de controle da natalidade, mas de cidadania, informações e meios para efetivar a autodeterminação reprodutiva.

Como afirmado por Bledsoe e Cohen há muitos anos, "adolescent fertility is affected by a wide range of rapidly changing factors acting through multiple, complex pathways we are only beginning to understand" (BLEDSOE; COHEN, 1993, p. 234). No Brasil, a má qualidade da educação associada com oportunidades limitadas de emprego poderia induzir um grande número de mulheres jovens a começar a família como uma opção mais atraente para suas vidas. Assim, uma grande porcentagem de mulheres adolescentes e jovens veem a fecundidade precoce e formação de uma família como a única possibilidade de ter uma vida diferente (HEILBORN, 1998). Em um melhor sistema educacional, não só em termos de cobertura, mas especialmente em termos de qualidade da educação, juntamente com um amplo mercado de trabalho decente e em uma sociedade mais igual para homens e para mulheres, deveria se esperar que grandes porcentagens de mulheres não escolhessem se tornar mães durante a sua adolescência ou juventude, como fizeram suas avós e mães em um passado patriarcal. Com isso, consequentemente a fecundidade de jovens poderia diminuir aos níveis observados em países mais desenvolvidos, ou pelo menos reduziriam as diferenças observadas entre as classes socioeconômicas no Brasil.

A comunidade internacional já chegou a um consenso sobre o que fazer. Tanto na Conferência de População de Desenvolvimento (CIPD), realizada no Cairo em 1994, quanto na revisão da Cúpula do Milênio, em 2005, a totalidade dos países do mundo concordou com a seguinte meta: " $5 \mathrm{~B}$ - Alcançar, até 2015, 0 acesso universal à saúde reprodutiva". Portanto, 0 que 0 mundo precisa não é 
de políticas para o controle da natalidade, mas sim de meios para garantir que as mulheres e homens coloquem em prática os seus direitos à saúde sexual e reprodutiva e os gestores precisam saber identificar melhor os grupos demandantes de políticas públicas que levem os direitos a todos os seguimentos da população.

A análise territorial associada à análise socioeconômica permite identificar e conhecer melhor os segmentos que não têm seus direitos reprodutivos assegurados e, com isto, pode-se propor programas e ações específicas, direcionadas e que respeitem os direitos sexuais e reprodutivos de todos, que tenham melhores resultados na redução da fecundidade não planejada entre adolescentes e jovens, para que estas, no momento que julguem ser mais adequado tanto para elas quanto para os parceiros e os filhos, possam colocar em exercício 0 direito à maternidade. 


\section{Referências}

ALVES, J. E. D. The context of family planning in Brazil, In: Cavenaghi, Suzana. (Org.). Demographic transformations and inequalities in Latin America: historical trends and recent patterns. 1 ed. Rio de Janeiro: ALAP, 2009, v. 8, p. 297-302.

ALVES, J. E. D. Transição da fecundidade e relações de gênero no Brasil. 1994. 152f. Tese (Doutorado) - Centro de Desenvolvimento e Planejamento Regional, Universidade Federal de Minas Gerais, Belo Horizonte, 1994.

AQUINO, E. M. L; et al. Adolescência e reprodução no Brasil: a heterogeneidade dos perfis sociais. Cad. Saúde Pública, v.19, suppl.2, p. S377-S388, 2003.

BERQUÓ; CAVENAGHI, S. Mapeamento socioeconômico e demográfico dos regimes de fecundidade no Brasil e sua variação entre 1991 e 2000. In: XIV Encontro Nacional de Estudos Populacionais, Caxambu (MG), ABEP, 2004.

BLEDSOE, C. H.; BARNEY, C. (Ed). Social Dynamics of Adolescent Fertility in SubSaharan Africa. Working Group on the Social Dynamics of Adolescent Fertility, National Academy of Sciences: Washington, D.C. p.224, 1993.

BRANDÃO, E.R. Gravidez na adolescência: um balanço biblioGráfico. In: HEILBORN, M. L. et al. (org.). 0 aprendizado da sexualidade: reprodução e trajetórias sociais de jovens brasileiros. Rio de Janeiro: Guaramond e Fiocruz, p.63-95, 2006.

BORGATO, L.; OLIVEIRA, M.C. Quem são as mulheres que engravidam antes dos 20 anos no Brasil? Uma análise dos fatores associados à gravidez na adolescência, In V Congresso da Associação Latino Americana de População, ALAP, 2012, Montevidéu. Anais do V Congresso da ALAP. Montevidéu: ALAP, 2012. p.19, 2012.

CAMARANO, A. A. Fecundidade e anticoncepção da população jovem. In: Comissão Nacional de População e Desenvolvimento. Jovens acontecendo na trilha das políticas públicas. v.1, Brasília: CNPD, IPEA, 1998.

CAMARANO, A. A. A hipótese de convergência dos níveis de fecundidade nas projeções populacionais. São Paulo, Revista da Fundação SEADE, v. 10, n. 2, 1996.

CALDWELL, J. C. Theory of fertility decline. London: Academic, 1982.

CARVALHO, J. A. M.; WOOD, C. A. Demografia da Desigualdade no Brasil. Rio de Janeiro: IPEA, (Série 27 PNPE), 1994.

CARVALHO, J. A. M.; PAIVA, P. T. A.; SAWYER, D. R. A recente queda da fecundidade no Brasil: evidências e interpretação. Belo Horizonte: CEDEPLAR/UFMG, 1981. (Monografia, 12), 1981.

CAVENAGHI, S.; BERQUÓ, E. Increasing Adolescent and Youth Fertility in Brazil: A New Trend or a One-Time Event?. In: Population Association of America: 2005 Annual Meeting, 2005, Filadélfia. Anais Population Association of America: 2005 Annual Meeting. Filadélfia: PAA,. p. 1-18, 2005. 
CAVENAGHI, S. Aspectos metodológicos e comparabilidade com pesquisas anteriores. In: Ministério da Saúde e Cebrap. (Org.). Pesquisa Nacional de Demografia e Saúde da Criança e da Mulher PNDS 2006: Dimensões do processo reprodutivo e da saúde da criança. 1 ed. Brasília: Ministério da Saúde, v. 1, p. 1332, 2009a.

CAVENAGHI, S. Legislación y práctica de la planificación familiar en América Latina: desigualdad de acceso a la contracepción. In: RODRíGUEZ WONG, L. (Org.). Avances y retrocesos en la Salud Sexual y Reproductiva en América Latina. 1 ed. Rio de Janeiro: ALAP, 2009b.

CAVENAGHI, S.; ALVES, J. E. D. Diversity of childbearing behaviour in the context of below-replacement fertility in Brazil. United Nations, Population Division, Expert Paper, N. 2011/8. Disponível em: http://www.un.org/esa/population/publications/ expertpapers/2011-8_Cavenaghi_Expert-Paper_FINAL_ALL-Pages.pdf, 2011.

CORREA, S.; ALVES, J. E. D. As metas do desenvolvimento do milênio: grandes limites, oportunidades estreitas?. Revista Brasileira de Estudos da População, Campinas: ABEP, v. 22, n.1, p. 177-189, 2005.

CORRÊA, H. A maternidade na adolescência e a educação formal: convergência e divergência interpretativas a partir de uma avaliação do Censo Demográfico 2000. In: IBGE. Escola Nacional de Ciências Estatísticas. Prêmio ENCE 50 anos: 0 censo 2000 e a pesquisa social no Brasil. Rio de Janeiro, Brasil. p. 79-131, 2009.

DINIZ, D.; MEDEIROS, M. Aborto no Brasil: uma pesquisa domiciliar com técnica de urna. Ciência \& Saúde Coletiva, 15(Supl. 1): 959-966, 2010.

FARIA, V. E. Políticas de governo e regulação da fecundidade: consequências não antecipadas e efeitos perversos. In: CIÊNCIAS sociais hoje. São Paulo, ANPOCS, 1989.

Furstenberg, F. JR When Will Teenage Childbearing Become a Problem? The implications of Western Experience for Developing Country, Studies in Family Planning, V. 29, N. 2, 1998.

HAAG, C. Humanidades I famílias encolhidas: Brasil em transição demográfica. Pesquisa FAPESP, 192, p. 76-81, 2012.

HEILBORN, M. L. Gravidez na adolescência: considerações preliminares sobre as dimensões culturais de um problema social. In: VIEIRA, E.M.; FERNANDES, M.E.; BAILEY, P.; MCKAY, A. (orgs). Seminário Gravidez na Adolescência. Brasília (DF): Cultura Editores Associados, 1998.

IBGE Fundação Instituto Brasileiro de Geografia e Estatística. Censo Demográfico, Rio de Janeiro: IBGE (múltiplos anos). Metodologia do Censo Demográfico 2000, Série Relatórios Metodológicos, V. 25, Rio de Janeiro, IBGE, 2003. 
JIMENEZ; M.; RODRIGUEZ-VIGNOLI, J. V. Evaluating the millennium development goal target on universal access to reproductive health: a view from Latin America and the Caribbean, In Cavenaghi, S. (Org. ) Demographic transformations and inequalities in Latin America: Historical trends and recent patterns, Serie Investigaciones N.8, Rio de Janeiro: ALAP, p. 243-289, 2009.

KOHLER H.P.; BILLARI, F.C.; ORTEGA, J.A. The Emergence of Lowest-Low Fertility in Europe during the 1990s, Population and Development Review, v.28, N. 4, p. 641-680, 2002.

LESTHAEGHE, R.; WILLEMS, V. Is Low Fertility a Temporary Phenomenon in European Union? Population and Development Review, V. 25, N. 2, p. 211-228, 1999.

MARTINE, G. Formación de la Familia y Marginalidad urbana en Rio de Janeiro. Centro Latino Americano de Demografia, Santiago de Chile, 1975.

MARTINE, G. Brazil's fertility decline, 1965-95: A fresh look at key factors, Population and Development Review 22: 47-75, 1996.

MERRICK, T.; BERQUÓ, E. The determinants of Brazil's recent rapid decline in fertility. Washington, National Academy, 1983.

MIRANDA-RIBEIR0, A.; et al. Reconstrução de histórias de nascimentos a partir de dados censitários: uma análise comparativa de duas metodologias. Revista Brasileira de Estudos de População (Impresso), v. 26, p. 21-35, 2008.

MOULTRIE, T.; DORRINGTON, R. Sources of error and bias in methods of fertility estimation contingent on the $P / F$ ratio in a time of declining fertility and rising mortality. Demographic Research, v.19, n.46, p.1635-1662, 2008.

OLIVEIRA, M. C.F.A.; VIEIRA, J. M. Pregnancy among adolescents and child welfare: Is the mother's age a determinant factor? In: International Population Conference, 26, 2009, Marrakech, Morocco. ANAIS IUSSP, 2009. 29p. Disponível em: http:// iussp2009. princeton.edu/download.aspx?submissionld=92806, acesso em agosto de 2010.

ORGANISMO ANDINO DE SALUD - Convenio Hipólito Unanue Comité Subregional Andino para la Prevención del Embarazo en Adolescentes. Monitoreo y Evaluación del Embarazo en la Adolescencia en la Subregión Andina: Indicadores y Línea de Base. Octubre de 2009. Disponível em http://planandinopea.org/sites/default/files/ Monitoreo\%20y\%20Evaluacion\%20del\%20 PAPEA\%2027.10.2009_0.pdf.

PAIVA, P. T. A. 0 processo de proletarização como fator de desestabilização dos níveis de fecundidade no Brasil. In: MIIRÓ, C. et al. Transição da fecundidade: análises e perspectivas. São Paulo: CLACSO, 1985.

PÉRPETUO, I. H.; RODRÍGUEZ WONG, L. Programas y políticas nacionales que afectaron el curso de la fecundidad en el Brasil. Seminário La fecundidad en América Latina y el Caribe: Transición o revolución, Santiago de Chile: CEPAL/ CELADE, 2003. 
POTTER, J. E. et al. Mapping the Timing, Pace, and Scale of the Fertility Transition in Brazil. Population and Development Review 36(2): 283-307, 2010.

RIOS-NETO, E.L.G. et al., Fertility decline in Brazil: a different tempo effect with strong consequences. In: Population Association of America Annual Meeting, Philadelphia, Pennsylvania, 2005.

RISI, E.; CAVENAGHI, S. Tendências do aborto induzido no Brasil entre $2000 \mathrm{e}$ 2010 a partir de estimação indireta dos registros hospitalares, In: V Congresso da Associação Latino Americana de População, ALAP, 2012, Montevidéu. Anais do V Congresso da ALAP. Montevidéu: ALAP, 2012. p. 19, 2012.

RODRÍGUEZ-VIGNOLI J. Reproducción adolecente y desigualdades: IV Encuesta Nacional de Juventud, Chile. Revista Latinoamericana de Población, V. 5, n. 8, p. 87-113, 2011.

STERN, C.; GARCIA, E. Hacia un Nuevo Enfoque en el Campo del Embarazo Adolescente, In Stern, C e Figueroa, J. G. (coords), Sexualidade y Salud Reproductiva. Avances y retos para la investigación, México, El Colegio de Mexico, p. 331-358, 2001.

UNITED NATIONS. Manual X: Indirect Techniques for Demographic Estimation, Population Studies, 81.New York: National Research Council, United States National Academy of Sciences, 1983.

VAN DE KAA, D. J. Europe's second demographic transition. Population Bulletin, Washington, v.42, n.2, p.1 - 59, 1987. 